This document is a manuscript version of the following article:

Title: Why do urban travelers select multimodal travel options: A repertory grid analysis

By: Clauß, Thomas; Döppe, Sebastian

Published in: Transportation Research Part A: Policy and Practice

Volume 93, November 2016, Pages 93-116

Publisher: Elsevier | Year: 2016

DOI: 10.1016/j.tra.2016.08.021

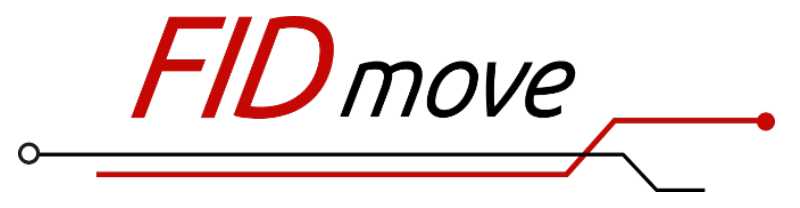

Brought to you by the Scientific Information Service for Mobility and Transport Research

Fachinformationsdienst Mobilitäts- und Verkehrsforschung

Website: www.fid-move.de

Repository: publish.fid-move.de

Contact: publish@fid-move.de

(C) 2016. This manuscript version is made available under the CC-BYNC-ND 4.0 license.

http://creativecommons.org/licenses/by-nc-nd/4.0/ 


\title{
Why Do Urban Travelers Select Multimodal Travel Options: A Repertory Grid Analysis
}

\author{
Thomas Clauß $\Re^{\mathrm{a}, \mathrm{b}}$ and Sebastian Döppe ${ }^{\mathrm{a}}$
}

\begin{abstract}
The increasing number of travelers in urban areas has led to new opportunities for local government and private mobility providers to offer new travel modes besides and in addition to traditional ones. Multimodal travel provides an especially promising opportunity. However, until now the underlying reasons why consumers choose specific alternatives have not been fully understood. Hence, the design of new travel modes is mainly driven by obvious criteria such as environmental friendliness, convenience etc. but might not consider consumers’ real or latent needs. To close this research gap, sixty in-depth interviews with urban travelers were conducted. To identify the perceptual differences of customers among different travel modes, the repertory grid technique as an innovative, structured interview method was applied. Our data show that urban travelers distinguish and select travel alternatives based on 28 perceptual determinants. While some determinants associated with private cars such as privacy, flexibility and autonomy are key indicators of travel mode choice, costs and time efficiency also play a major role. Furthermore, by comparing travel modes to an ideal category, we reveal that some perceptual determinants do not need to be maximized in order to fulfill customer needs optimally. A comparison of consumers' perceptual assessments of alternative travel modes identifies specific advantages and disadvantages of all alternatives, and provides fruitful implications for government and private mobility providers.
\end{abstract}

Keywords: Multimodal travel options; perceptions of travelers; determinants of travel mode choice; repertory grid technique

${ }^{a}$ Philipps-University of Marburg, ${ }^{b}$ corresponding author (clausst@uni-marburg.de) 


\section{Introduction}

Due to the growing number of citizens living in urban areas, policy-makers and mobility providers face challenges and opportunities in offering alternative travel modes. Travelers show an increasing willingness to combine multiple modes of transport (e.g. Kuhnimhof et al., 2012). Multimodal travel offers the complementary usage of different travel modes such as public transport, free-floating car sharing and bike sharing. As these innovative travel modes generally increase customers' satisfaction with transport systems (Lerner, 2011) they can be seen as a valuable starting point for firms and policy-makers to create new business models and services to fulfill customer needs for urban travel. The transition from monomodal (e.g. car) to multimodal mobility (combining different travel modes) enables a wide range of new market participants to act as mobility service providers. Just recently, several web-based applications were introduced in Europe that help travelers to automatically plan multimodal trips (e.g. waymate.de, fromatob.de or wanderio.com).

However, multimodal travel options are not well established and suffer from limited customer acceptance (Grotenhuis et al., 2007; Kramers, 2014). Studies show that due to the logistical complexity of self-selected multimodal options and potential problems at the interfaces between travel modes, monomodal options are often preferred to self-selected multimodality (Lerner, 2011). Since not all innovative multimodal travel options are successful, a detailed understanding of the determinants of travel mode choice and the adaptation of innovative new travel modes is required. Previous studies have tried to identify the main determinants of travel mode choice to understand the underlying decision-making process of the customer (e.g. Beirão and Sarsfield Cabral, 2007; Guiver, 2007; Mann and Abraham, 2006). However, these studies focus on the comparison of traditional travel modes (i.e. public transport vs. private car) but do not consider innovative multimodal travel options. Therefore, research so far does not capture the relevant determinants of travel mode choice related to new offerings. This constitutes a relevant research gap, as being able to influence factors affecting the consumer's acceptance of multimodal 
solutions determines the success of innovative offerings in the realm of urban travel and helps public policy-makers to address future urban travel requirements.

We address this research gap by using the repertory grid technique (RGT), an interview method which is new in travel mode research. It enables the identification of travelers' underlying cognitive determinants of even unconscious decisions. We contribute to research on travel mode choice in three ways. First, we extend the existing knowledge by identifying a full set of perceptual determinants that urban travelers rely on when selecting different travel modes. This provides a more nuanced understanding of the criteria that drive the decision-making process of urban travelers. Second, we identify those key travel mode determinants which are most important in addressing the needs of urban travelers. Third, based on these key travel mode determinants, we assess the specific characteristics of innovative multimodal travel options to other traditional travel modes and an “ideal” option. Our results provide policy-makers and practitioners with a relevant set of determinants that can be addressed when designing and positioning services and business models in urban travel.

\section{Literature overview}

Previous studies identified a variety of determinants that influence travel mode choice (Buys and Miller, 2011). These determinants were in most cases related to a priori defined criteria such as: trip purpose (Murtagh et al., 2012) situational aspects (Ben-Elia and Ettema, 2011; Khattak and De Palma, 1997), land use factors (Chatman, 2008; Kenworthy and Laube, 1999; Su, 2010), population characteristics (Taylor et al., 2009) and habitual behavior (Verplanken and Aarts, 1999). More general studies tried to aggregate determinants of travel mode choice which were assumed to capture the relevant determinants for choosing a specific travel mode (Lois and López-Sáez, 2009). Accordingly, existing determinants can be grouped into affective, symbolic (Beirão and Sarsfield Cabral, 2007; Hiscock et al., 2002) and instrumental factors (Gardner and Abraham, 2007). Table 1 summarizes the relevant travel mode determinants in previous research. 


\section{Insert Table 1 about here}

\subsection{Instrumental determinants of travel mode choice}

Instrumental determinants, such as time efficiency and flexibility refer to general practical aspects of mode choice (Anable and Gatersleben, 2005) and are driven by a desire to maximize the expected utility of the transport mode in relation to individual preferences (Gardner and Abraham, 2007; Steg, 2005)

Gardner and Abraham (2007) identify the monetary cost of using a travel mode as one of five core determinants of mode choice. All participants in their study, independent of their income level, tend to reduce their travel expenses. However, when measuring the travel expenses of using a private car the study found that travelers often only count the running costs of their vehicle, without including road tax, insurance or the depreciation of the vehicle. Beirão and Sarsfield Cabral (2007) discover that lower costs of public transport do not necessarily affect the switching intention of car users to public transport in the metropolitan area of Porto, Portugal. These findings are supported by Arentze and Molin (2013) who find a negative impact of perceived travel costs on selecting either a monomodal or multimodal travel option. Interestingly, they also find that sensitivity to costs is not homogeneous. Ticket costs or costs for park and ride are perceived more negatively than those for fuel, explaining limited switching intentions to public transport.

Besides financial costs, time-efficiency has been highlighted as an instrumental determinant of travel mode choice (Buys and Miller, 2011). Time-efficiency refers to the individual and selfrelated experiences of the traveler (Hagman, 2003). Vij et al. (2013) segment urban travelers based on their modal preferences. Two of three of these segments, the habitual car drivers and the multimodal travelers are significantly time-sensitive when choosing a transport mode. Examining the impact of instrumental and affective determinants of travel mode choice on travel satisfaction Susilo and Cats (2014) emphasizes the importance of travel time for car and public transport 
users. Car drivers who favor their travel mode over public transport assess the time-related advantages as absolute and show a high reluctance to change their mode choice behavior. Other efforts such as planning (Guiver, 2007) or physical effort are included in the costs of travel.

A third prominent instrumental determinant is flexibility. Jensen (1999) shows the importance of flexibility for being independent in terms of time and place of departure. Her results provide evidence that a more flexible public transport system is preferred. Flexibility is a reason for preferring private cars over public transport. In their study on the factors that affect bicycle use Fernández-Heredia et al. (2014) also find flexibility to be a key determinant of travel mode choice. Other aspects that relate to flexibility and thus determine especially ad hoc travel mode choice include availability (Hagman, 2003), route choice (Guiver, 2007) and the dependence on weather conditions (Hiscock et al., 2002).

Studies have analyzed convenience factors (Beirão and Sarsfield Cabral, 2007), such as service degree (Hine and Scott, 2000), healthiness (Buys and Miller, 2011) and safety (Beirão and Sarsfield Cabral, 2007). These factors were shown to increase the willingness to switch between travel modes. However, these factors are highly dependent on the destination and purpose of the journey (e.g. leisure time activities vs. travel to work) (Anable and Gatersleben, 2005).

Although the existing literature has already identified numerous instrumental determinants of mode choice, and quantitative studies have shown their relevance for the decision-making process (Friman et al., 2001), a holistic picture of instrumental determinants in terms of multimodal travel options and their specific requirements has not yet been produced.

\subsection{Affective determinants of mode choice}

Affective determinants of mode choice include aspects which are inherently linked to individual preferences. These comprise autonomy, freedom, fun to drive, stresslessness, privacy, relaxation and comfort (e.g. Guiver, 2007; Hagman, 2003; Hine and Scott, 2000). Anable and Gatersleben (2005) describe affective determinants of travel mode choice as feelings evoked by travelling. In 
some ways, affective determinants are the personal expressions of instrumental attributes of travel modes. Therefore, affective determinants comprise travellers' perceptions about travel modes from a holistic view that includes emotional aspects of the decision-making process.

Literature emphasizes the perceived privacy as an important determinant of mode choice (e.g. Gardner and Abraham, 2007; Guiver, 2007). Privacy concerns the available personal space of a particular travel mode including the protection from contact with others (Gardner and Abraham, 2007). Participants of focus groups in the UK (Guiver, 2007) describe the inside of the car as a safe and private space, a place which provides control over the environment and prevents intrusion by other people (e.g. by closing the windows and locking the doors). In particular, commuters experience the solitary personal space as positive. This is because privacy helps to reduce stress and gives room for relaxation (Guiver, 2007; Hine and Scott, 2000).

Freedom and autonomy have been shown to be key drivers for using a private car (Guiver, 2007; Hagman, 2003; Hiscock et al., 2002; Mann and Abraham, 2006), representing the possibility to live by one's own laws (Stradling, 2002). Hiscock et al. (2002) identify the feeling of control as a source of autonomy. This speaks against the choice of travel modes with low reliability, as delays and hold-ups are beyond individual control. Dependency on the actions and decisions of others (e.g. routes and time plans) is something people tend to avoid (Mann and Abraham, 2006).

Interestingly, most of the positive affective determinants have been linked to the use of private cars (Hagman, 2003). Ellaway et al. (2003) reveal that people with car access gain more affective benefits (e.g. feelings of autonomy and privacy) then public transport users. Steg (2005) also finds that affective determinants of mode choice related to autonomy and fun to drive have a stronger impact on the level of car use than instrumental determinants. However, the implications of these findings are limited, as multimodal travel options lead to more complex selection decisions compared to the choice between car and public transport. 


\subsection{Symbolic determinants of mode choice}

Status, prestige and personal identification constitute the symbolic determinants of travel mode choice (Beirão and Sarsfield Cabral, 2007; Buys and Miller, 2011; Hiscock et al., 2002; Mann and Abraham, 2006). Symbolic meaning can be distinguished into social expression and a social identity process (Lois and López-Sáez, 2009). The former describes a process related to selfpresentation. Cairns et al. (2014) argue that for young people, having a car can help them to portray and define themselves as adults. The social identity process refers to the desire to express group characteristics by the choice of a specific travel mode to underline one's own identify. In this case, travel modes reflect an already established and previous existing social role. For example, owning a four-door luxury saloon can act as a symbol of having achieved in life.

Previous research has mainly related symbolic aspects to private car use. This is because symbolic attributes of travel modes are usually associated with ownership. Steg (2005) finds that the use of the private car can be associated with the feeling of power. Mann and Abraham (2006) reveal the personal identification with the private car as a key determinant of mode choice. Participants of in-depth interviews described car ownership as an important part of their identity. Steg (2003) shows that some fervent car users perceive their cars to be symbols of freedom, independence and social status, each providing a unique independent value. Additionally, cars also serve as symbols of high income and can represent masculinity (Hiscock et al., 2002).

Besides the effects of ownership, social identification can also be linked to behaviors such as doing something good, behaving responsibly or even adapting innovations (Grewal et al., 2000). In line with new technological opportunities and changing requirements for urban travel, the meaning of social identification can switch to alternative attributes. For example, the choice of travel mode can be a "symbol of an existing social role as an environmentalist" (Cairns et al., 2014 p. 112). Such symbolic meanings might especially be important for new collective transport options (e.g. free-floating car sharing), which provide novel identities within a specific network of people (Cairns et al., 2014). 


\subsection{Limitations of previous studies}

As shown before, a significant number of studies have investigated the determinants of travel mode choice under different context conditions. Two main limitations arise from the literature that should be addressed in future research. (1) Limited scope: Existing literature with a focus on identifying instrumental, affective and symbolic determinants mainly researched the use of traditional travel modes such as public transportation and the use of private cars (Beirão and Sarsfield Cabral, 2007; Gardner and Abraham, 2007; Hiscock et al., 2002; Redman et al., 2013; Steg, 2003). Non-instrumental aspects, which are highly individual and subjective in nature, were primarily analyzed concerning the discrete choice between public transport and the use of private cars. Including two additional travel modes: cycling and walking Gatersleben and Uzzell (2007) indicates that these modes are perceived significantly differently in terms of affective determinants of mode choice. Anable and Gatersleben (2005) substantiate these results as the inclusion of cycling and walking in their comparative study of travel modes amplifies new differences in affective (e.g. stress and relaxation), and instrumental (e.g. flexibility and convenience) determinants of mode choice. There are no studies that take into account the broad range of traditional and new travel modes available in urban areas. Hence, the investigation of travelers' mode choice in real life situations requires an extended scope of analysis. Previous studies did not consider innovative travel modes. Especially in urban areas, new travel modes such as bike-sharing or free-floating car sharing were recently introduced to address latent customer needs. Hence, the determinants that were identified before are most likely not comprehensive and not generalizable as their focus is too narrow. (2) Limited comparability: The existing literature provides a diffuse picture of the particular importance of each determinant of travel mode choice. Most results are based on qualitative investigations of rather small samples. Depending on the specific travel modes that were considered in a study, instrumental (Eriksson et al., 2008; Van Exel and Rietveld, 2009), affective and symbolic (Ellaway et al., 2003) determinants each were identified as primary determinants of travel mode choice. Hence, current 
results do not provide a clear picture about the importance of specific determinants of travel mode choice in complex multimodal travel systems. Therefore, insights about the importance of constructs regarding their influence on travel mode choice are scarce. As most travel modes were usually omitted, comparative implications in multimodal settings are limited.

Analyzing determinants for travel mode choice based on a more comprehensive choice set of potential travel modes allows for a critical assessment of previous determinants and an identification of new determinants that can be addressed by innovative travel modes (Cairns et al., 2014). The objective of this study is to explore determinants of travel mode choice considering traditional (e.g. bus and private car) and innovative urban travel modes (e.g. bikesharing and free-floating car sharing). Furthermore, multimodal travel options are added to complement the real-life consideration set of urban travelers. To provide fruitful implications for the design of new travel offerings, innovative multimodal travel options and "ideal” solutions are compared.

\section{Methodology}

\subsection{Repertory grid procedure}

As our purpose is to identify the underlying individual cognitive perceptions of travelers related to different travel modes, we break away from traditional survey-based evaluation. We applied the RGT (Kelly, 1955) to elicit the personal constructs (i.e. individual perceptual attributes of a given subject) of how respondents perceive travel alternatives in real-life experiences. The RGT is a cognitive mapping tool used in a structured interview to elicit and evaluate mental models of individuals regarding a subject of analysis (Wright, 2004). This interview is complemented by a quantitative assessment of the results of the interview, making the RGT an approach that inherently links the advantages of qualitative and quantitative methods. RGT interviews comprise four iterative stages (Easterby-Smith et al., 1996) which lead to a completed matrix as Figure A.1 exemplifies and illustrates for one respondent. Figure A.2 gives an overview on the steps of the 
RGT interviews and the subsequent data analysis procedure.

\subsubsection{Definition of the focus of the study}

It is necessary to define precisely what is to be explored in the investigation because the information provided to the respondents and the manner of questioning determines the breadth of the constructs elicited (Jankovicz, 2004). The present study focuses on the exploration of the perceptual determinants regarding different travel modes for urban travellers.

\subsubsection{Selection of appropriate elements}

The identification of personal constructs in the RGT is based on the comparison of so called elements. Elements - according to the RGT - are the objects to which the personal constructs relate. Elements are specific representations of the unit of analysis (e.g. specific travel modes). As the selected elements determine which alternatives are considered during the elicitation of personal constructs, they define the scope of the analysis (Wright, 2004). For the present study, elements are travel modes representing a typical consideration set of an urban traveler. The elements need to cover all relevant characteristics of the unit of analysis and should be distinct from each other. It is necessary to identify elements that are wide and yet specific enough to elicit an adequate spectrum of perceptions about a domain (Wright, 2004). Researchers conclude that this can be achieved by using nine to fifteen elements (Easterby-Smith et al., 1996; Jankovicz, 2004). Based on our literature review, and the objective of our study to capture innovative travel modes, travel modes can be differentiated based on two criteria: 1) multimodality (low-high) and 2) innovativeness (low-high). Using these, we classify travel modes into four groups (Figure 1).

\section{Insert Figure 1 about here}

Real travel modes were aligned with these categories. In addition to traditional and therefore more obvious travel modes (car, public transport etc. - together, seven elements), we identified relevant new ideas and prototypes in the innovative multimodal area. Thus, we undertook web 
research on new mobility services and developed a list of potential alternatives. We discussed these ideas in three interviews with managers of public transport companies (e.g. Hamburger Hochbahn) to collect the most relevant multimodal and innovative travel modes. We added two innovative (city bike and city car) and three multimodal travel modes (smartphone application, door-to-door service, and all-in-one offer) to our list. Besides the evaluation of real elements, RGT researchers proposed integrating fictitious ideal options (e.g. Honey, 1979; Jankovicz, 2004) in order to have a reference point for the evaluation by the interviewee. Therefore, we added two ideal elements (ideal for work and ideal for leisure) to our list. To ensure that all participants had a common understanding of these "ideal” travel modes we asked the participants to think about the characteristics of two individual optimal travel modes based on their subjective preferences. First, we asked them to think about their expected characteristics of an "ideal” travel mode for leisure travel, which they would prefer for private, voluntary activities during their leisure time. This ideal mode should optimally suit their subjective needs and requirements outside their working environment. On the other hand, the "ideal" travel mode for work represents the individual best possible solution for travelling from home to work. We asked participants to think about regular work related travel like daily commuting including all activities with a professional purpose. This also includes travel to all educational institutions. Unlike the other elements, "ideal" travel modes were not used during the construct elicitation process. Nevertheless, the participants rated all elements including the "ideal" travel mode for leisure and for work based on their own perceptual constructs. Therefore, we enabled the participant to evaluate existing travel modes in relation to their individual optimum. Our initial list of elements was discussed among the team of researchers to ensure that all relevant travel modes were considered but complexity was still manageable. Ultimately, 14 elements were used (see Table A.1 for a detailed description). 


\subsubsection{Elicitation of constructs from the elements}

Constructs - according to the RGT terminology - are the dimensions which individuals use to describe and differentiate the individual elements (Wright, 2004). In our study, constructs are the determinants of travel mode choice. A common method for eliciting constructs is "triading" (Easterby-Smith et al., 1996). This approach utilizes the comparison of cards on which the different travel modes are written. During the interview, the respondent is provided with three cards (a triad) at a time and is asked the so called Kelly question: "Regarding which determinant are two of these travel modes similar but different from a third one.” The interviewee then provides a word or phrase describing a characteristic that unites two travel modes (Wright, 2004). As the individual meaning of these constructs might vary, interviewees are further asked to name a contrasting word (e.g. good vs. bad indicates a different meaning than good vs. great) that describes in what way the third travel mode is different. The comparison of triads forces the interviewees to also elicit non-obvious differences. In the study, each respondent was provided with six predefined triads of travel modes. This number proved to be sufficient but still manageable within an adequate interview duration (on average the interviews took 73 minutes).

The two ideal travel modes were not used in the triading process, as these are not real objects and thus cannot be characterized by specific determinants of travel mode choice. Interviewees were not allowed to repeat constructs for more than one triad to stimulate deeper reflection (Goffin et al., 2006). However, if more than one construct was mentioned for the same triad, these were entered in two different lines of the grid. To obtain approximately the same number of observations for each element, all 220 possible triad combinations (binomial coefficient: three out of twelve) were listed. The triads on this list were randomly assigned to the thirty interviews with users of public transport and again to the thirty interviews with users of private cars. We thereby

ensured that each triad was only used once for each group of interviewees. A record sample of one RGT interview is provided in Figure A.3. 


\subsubsection{Linking constructs to elements.}

During the interviews, all elicited determinants of travel mode choice were written in the rows of the grid with the elements heading each column. After the elicitation phase, respondents rated each of the 14 elements (including the two ideal ones) based on their own perceptual constructs. We used a seven-point scale ranging from 1 (construct pole fully applicable) to 7 (contrast pole fully applicable). As the respondents provided a construct pole and an opposite contrast pole, this rating scale was similar to a semantic differential scale (Fransella and Bannister, 1977).

\subsection{Sample}

To ensure that all participants were aware and could use the same set of alternative travel modes, we interviewed only residents living in the metropolitan area of Hamburg, Germany. With about 1.7 million residents, Hamburg is the second largest city in Germany and the eighth largest city in the European Union. Our sample thus provides insights about a city which is confronted with the challenges of growing demand for urban mobility. Furthermore, some innovative travel modes (e.g. free-floating car sharing) have already been successfully implemented in Hamburg. Therefore, most users are well aware of the characteristics of traditional and innovative travel modes. Although, the focus on one metropolitan area could limit the generalizability, Hamburg can be regarded as a typical example of a large modern European city such as Barcelona (Marquet and Miralles-Guasch, 2014), Zurich (Habib et al., 2013), Paris (de Palma and Picard, 2005) etc. Hence the results represent the behavior of residents of agglomerated, high density urban areas which provide a certain variety of alternative travel modes.

Before the large-scale interview study, we conducted six pretest interviews with randomly selected urban travelers. Pretests are recommended to learn how to guide the interviewees without influencing the personal construing (e.g. Jankovicz, 2004). Furthermore, we assessed if the interviewees understood the elements and the interview procedure. The final study included a 
large number of 60 structured in-depth telephone interviews with frequent urban travelers. ${ }^{1}$ To prevent biased results from individual preferences and habits, we selected 30 private car owners and 30 public transport users aged between 22 and 63 with a share of 53\% being female and 47\% being male. Hence, our sample covered people with a broad variety of perceptions regarding urban travel. The interviews lasted 60 to 90 minutes and were conducted in late 2012. Each of the 60 interviewees elicited perceptual determinants based on six triads. Due to some cases with more than one construct per triad, altogether $366\left(\mathrm{~N}_{\text {private }}=183, \mathrm{~N}_{\text {public }}=183\right)$ determinants of travel mode choice were retrieved.

\section{Data analysis and results}

\subsection{Aggregation of determinants of travel mode choice}

The data were aggregated using the bootstrapping ${ }^{2}$ core-categorization procedure (Jankovicz, 2004). In this approach, the 366 elicited determinants of travel mode choice out of the 60 interviews were sorted into subgroups of the same meaning. In cases where the same dimensions were elicited but in an opposite way (e.g. if one respondent elicited the construct pole "fast" and another one the construct pole "takes time", both referred to the same determinant but in an opposite direction) construct poles and contrast poles were interchanged and ratings were recoded. This process was iteratively repeated until homogeneous groups of similar meaning were retrieved. Two experts performed this procedure independently, each of them familiar with the travel modes and the course of the interviews. In line with Goffin and Koners (2011), we assessed the reliability of our aggregated constructs by comparing the independent results of these two coders. 91\% agreement in the public transport sample and $96 \%$ in the private car

\footnotetext{
1 This number can be considered appropriate as the in-depth interview approach of the RGT usually allows eliciting a comprehensive list of constructs with small samples of about 15 to 25 subjects (Dunn et al., 1986; Tan and Hunter, 2002). For example, Dunn et al. (1986) already elicited 23 distinct constructs after 10 of 17 interviews, which means that no additional constructs were elicited during the last 7 interviews. We assessed ten more recent article that applied the RGT in different management disciplines (Davis and Hufnagel, 2007; Goffin and Koners, 2011; Goffin et al., 2006; Konig et al., 2011; Malmström et al., 2014; Micheli et al., 2012; Panagiotou, 2007; Raja et al., 2013; Wright, 2004, 2008). Sample sizes in these studies ranged from five to 46 interviews with the median being 27.

${ }^{2}$ Different from its meaning in statistical analyses, bootstrapping in terms of the RGT means the content-analysis based, stepwise aggregation process in which each individual construct is compared with each of the others to build categories of a common meaning (see Jankovicz, 2004, p. 285 for a step by step procedure).
} 
sample were achieved, which exceeded the threshold of 90\% (Jankovicz, 2004) and indicated a high reliability of our aggregated constructs. After completion, the experts compared their results and discussed different groupings until consensus was reached. Finally, the 366 constructs were assigned to 28 aggregated determinants of travel mode choice. These, including exemplary quotes from the interviews, are shown in Table 2. A collective super grid (Wright, 2004) was created by calculating the average rating for each aggregated construct (see Table A.2). This super grid relates the determinants of mode choice to each of the 14 travel modes.

\section{Insert Table 2 about here}

\subsection{Identification of perceptual dimensions of travel mode choice}

To address the first research objective for identifying perceptual determinants of urban travelers regarding different travel modes we conducted an exploratory principle component analysis with oblique rotation based on the super grid (Wright, 2004). This approach was appropriate as many correlations exceeded .30 and communalities varied from .99 to .88. Applying Kaiser-criterion (extraction of only factors with eigenvalues $>1$ ) and the scree test, we extracted six factors, which explained $91.7 \%$ of the total variance. These factors represented the main dimensions of travel mode choice (Table 3). We labeled factors based on the constructs that showed high factor loadings.

Factor 1 comprised six determinants and accounted for $32.8 \%$ of the total variance in the data. This factor included autonomy, fun to drive, personal safety, privacy and flexible route choice. Autonomy as described by the respondents is the feeling of having control over the environment, being independent from the decisions and actions of others, and playing an active part as a road user and creator of their own life. Personal safety expresses the feeling of being protected from violations or crime as well as disputes with others. Privacy describes the possibility of having one's own solitary space without the intrusion of others. Flexible route choice directly corresponds with autonomy. While most public transport might require significant detours, self- 
steered and private travel modes leave the decision of the route to travelers. These constructs are similar to the group of affective determinants outlined in the literature review. In line with the literature, we labelled this factor "affect”. Interestingly, factor 1, which only contained noninstrumental determinants, explained most of the variance in travel mode choice.

We labeled Factor 2 "convenience". Seven determinants of travel mode choice loaded high on this factor and explained $24 \%$ of the total variance. The factor included determinants which described the degree of necessary individual effort to use a particular travel mode: physical effort, weather independency, healthy activity, traffic safety, transportability and time efficiency. This factor represented determinants with instrumental benefits for urban travelers.

Factor 3 accounted for $18.8 \%$ of the variance and consisted of three determinants of travel mode choice reflecting the perceived "stress" when using urban travel modes. The determinants were long-distance capability, stresslessness and low maintenance. In contrast to previous studies, in our study these determinants extracted a new independent factor and were not part of the affect dimension. Respondents perceived stress as the mental effort required for using certain travel modes. This effort in urban areas is closely linked to situations such as searching for a parking lot or coping with uncertainty while waiting for a bus. This factor addresses those aspects that cannot be planned in detail prior to the travel decision, as they might occur during travel.

Factor 4 comprised three determinants of travel mode choice, which explained $10.3 \%$ of the variance. We labeled this factor "individuality”, as it consisted of the determinants adaptivity, innovativeness and service degree. Compared to existing studies, this factor builds a new dimension that was completely overlooked in previous research. Adaptivity describes the ability to fulfill individual, situational mobility related requirements. Respondents judged the possibility to adapt their transport alternative to their fast changing and highly individual mobility needs as beneficial. Since the factor integrated the construct of innovativeness, it emphasized the potential of new travel modes. The service aspect shows that besides new design features, adaptivity can be fostered through new service offerings (e.g. preference-based routing). 
Factor 5 accounted for only $5.8 \%$ of the variance. It was labeled "cost” because of the high factor loadings of the determinants cost transparency and cost efficiency. Furthermore, the inclusion of the sustainability aspect showed that travelers perceive environmental consequences of their travel mode choice as costs. This factor was categorized among instrumental determinants in previous studies. Our result shows that these "real” costs are fundamentally different from the individual instrumental efforts.

Factor 6 was called "flexibility" and explained only $3.8 \%$ of the variance. This factor further differentiated the overall instrumental dimension. Determinants such as the ease of use, local availability, temporal flexibility and reliability determine the degree to which urban travelers could spontaneously decide upon the use of a particular travel mode.

\section{Insert Table 3 about here}

\subsection{Identification of key determinants of travel mode choice}

Addressing the second objective to identify key determinants of travel mode choice, which are most important in addressing the needs of urban travelers, we applied the approach of Goffin et al. (2006) for identifying key constructs in RGT data. Therefore, a construct should fulfill two requirements in order to qualify as a key construct: frequency and variability. A determinant which was frequently mentioned by the respondents in the interview process is likely to be more important in the minds of the respondents. The relative frequency necessary for identifying key constructs is left open for interpretation in the RGT literature (Goffin et al., 2006). Since we identify a relatively long list of determinants from just a few triads, an important construct should have been mentioned by at least $20 \%$ (12) of the respondents.

While frequency provides indication about the importance of a construct, it can also indicate that one attribute is more obvious than another one or can be easily articulated (Goffin and Koners, 2011). Furthermore, frequency does not reveal the relative importance of a construct related to 
different travel modes. The relative importance of a construct can be further quantified by the variability as a measure of the spread of its ratings compared to all the other constructs. Following the calculation method as described in Goffin et al. (2006), the average normalized variability per construct was $16.39 \%$ (Table 4). Constructs with an average normalized variability (ANV) above this value were classified as important and thus highlighted.

Five constructs exceeded the frequency and the variability threshold and were thus key determinants of travel mode choice. These were the perceived privacy ( $n=22, A N V=25.41$ ), flexible route choice ( $n=20, A N V=18.11)$, autonomy $(n=15, A N V=20.28)$, sustainability $(n=13$, ANV=19.86) and stresslessness ( $n=12, A N V=17.07)$. Four (80\%) of these key constructs were of a non-instrumental nature. This is a relevant finding for the positioning and design of new travel modes. While instrumental aspects might be more obvious (i.e. high frequency counts), they discriminate to a lesser degree between the travel modes than affective ones (i.e. high ANV). Hence, for advertising new multimodal travel options, it might be more relevant to address emotions during travel, rather than the travel mode itself (e.g. autonomy in public transport might be increased by a greater information transparency regarding departures and interfaces between travel modes). Besides the affective determinants, sustainability complements the set of key determinants for travel mode choice. This shows that nowadays environmental responsibility is a highly relevant determinant when selecting travel modes, especially in the mind of urban travelers.

\section{Insert Table 4 about here}

\subsection{Comparison of travel modes}

In order to address the third objective to assess the specific characteristics of innovative multimodal travel options and to deduce relevant design implications for these, we compared the particular characteristics of the different travel modes. Specifically, we contrasted the average ratings of all elicited constructs for the primary travel modes that represented each of the four 
groups of travel modes as described in Figure 1: the smartphone application (innovative multimodal), the all-in-one offer (traditional multimodal), subway and the private car (traditional monomodal), free-floating car-sharing (innovative multimodal) and the "ideal" travel to work mode (Figure 2 and 3). This allowed us to contrast innovative multimodal travel options with the most relevant urban travel alternatives to date (Pooley and Turnbull, 2000). In order to test the significance of mean differences among travel modes, we conducted an ANOVA with Tukey's HSD post-hoc test. Table A.3 shows all significant mean differences $(\mathrm{p}<0.05)$ for the selected travel modes.

Figure 2 shows that regarding the three key determinants of travel mode choice which belong to the affect dimensions privacy, flexible route choice and autonomy, the private car significantly outperformed the subway. In comparison to this rather obvious observation other interesting implications can be found. First, multimodal travel options were evaluated as significantly better than traditional public transport. While these still rely to a significant degree on public transport, the limitations of privacy, flexible route choice and autonomy are reduced. High service offers based on mobile applications provided an adequate solution in the mind of participants. Regarding flexible route choice, there was not even a significant difference between the private car and the smartphone app. Second, innovative travel modes such as free-floating car sharing did not show significant differences to the private car. Third, when considering the hypothetical ideal travel mode, not all determinants needed to show the maximum values. All travel modes except for public transport were as good as the ideal mode regarding flexible route choice and autonomy. Regarding privacy, the value of the private car was significantly higher as compared to the value of the ideal travel mode. This speaks for the wish of travelers to have some social interaction.

Interestingly, the key determinant, stresslessness, was not significantly different among the available travel modes. However, a significant difference could be seen in comparison to the ideal mode. This indicates a latent need of urban travelers for travel modes that reduce stress 
during travel.

In terms of the determinants of the newly found dimension "individuality", multimodal travel options were significantly better when compared to public transport and the private car. Innovativeness was a criterion that discriminated multimodal offers and free-floating car sharing from other traditional travel modes. The situational adaptivity, which allows a flexible mode choice depending on the situational requirements of the traveler, is fulfilled by multimodal travel options. This demand cannot be fulfilled by the private car.

Figure 3 shows the remaining dimensions of convenience, cost and flexibility. Out of these, sustainability, which belongs to the perceived costs, is the last key determinant. In general multimodal travel options were perceived as significantly cheaper than the private car. Sustainability aspects differentiated strongly between the considered travel modes. All multimodal travel solutions and especially the subway outperformed the private car when assessing the environmental friendliness of urban travel modes. However, only public transport could meet the high expectations (ideal mode) of urban travelers.

\section{Insert Figure 2 and Figure 3 about here}

\section{Discussion}

\subsection{Key Research Findings}

Based on the data of 60 telephone interviews, the application of the RGT enabled the elicitation of 28 determinants of travel mode choice when considering traditional and innovative travel modes. These determinants represented six perceptual dimensions: Affect, convenience, stress, individuality, cost, and flexibility. By assessing the importance of particular determinants of travel mode choice, we identified privacy, autonomy, stresslessness and flexible route choice as affective, and sustainability as instrumental key determinants of travel mode choice. Finally, we characterized various traditional and innovative as well as monomodal and multimodal travel by 
comparing these with each other and with ideal modes. On the one hand, our results support previous research on the determinants of travel mode choice, on the other hand new and surprising results were unveiled. We particularly support two sets of findings:

a) Support of important determinants of travel mode choice from previous studies: Our identified key determinants of travel mode choice are in line with the results of several previous analyses. We support the qualitative results of Gardner and Abraham (2008) who identify privacy as one of the main determinants of travel mode choice. They relate privacy to the need for protection from unwanted social and physical conditions as well as to a desire for privacy from unwanted intrusions. Mann and Abraham (2006) also identified autonomy and stresslessness as major affective determinants. They found that travelers try to avoid being dependent on the actions of others and feel a lack of control over their own life. The feeling of dependency on external conditions leads to stress and a feeling of inconvenience. The positive effect of flexible route choice on the likelihood of car use supports the results of Johansson et al. (2006). Sustainability, as the last key determinant, is perceived as a cost-related element of urban traveling. This supports the idea that urban travelers perceive pollution associated with their use of travel modes as real costs affecting the environment (Nilsson and Küller, 2000).

b) Advantages of the private car: In line with other studies (e.g. Beirão and Sarsfield Cabral, 2007; Cairns et al., 2014; Redman et al., 2013; Steg, 2003), we also find that the private car has significant advantages regarding affective determinants when compared to public transport.

In addition to the support of previous research contributions, our study provides five key insights for urban travel that are new or contrasting in comparison to previous results.

a) Relevance and dimensionality of affective determinants of travel mode choice: When compared to other studies (e.g. the meta analysis of Gardner and Abraham, 2008) we find an exceptionally high relevance of affective determinants of travel mode choice in urban areas. Affective constructs explained the lion share of the variance in the factor analysis and accounted for four out of five key determinants of travel mode choice. Therefore, we conclude that 
instrumental aspects are considered as hygiene factors but do not sufficiently differentiate travel modes. Furthermore, affective criteria separate into two independent factors - affect and stress. These results show that perceptual determinants of travel mode choice are more differentiated than assumed by the previous literature.

b) Absence of symbolic determinants of travel mode choice in urban travel: Interestingly, in contrast to previous studies (Beirão and Sarsfield Cabral, 2007; Buys and Miller, 2011; Jensen, 1999), we did not find symbolic determinants of travel mode choice in our study. This might be a logical consequence of the changing conditions for urban travelers (Cairns et al., 2014). Particularly, the meaning of cars as status symbols has decreased (Firnkorn and Müller, 2012), in favor of other benefits such as travel time reductions or cost saving enhancements.

c) Meaning of individualization and innovation: In addition to previous work in the field, we identify individuality as a new perceptual dimension for travel mode choice. This includes situational adaptivity as a latent need of urban travelers, which describes the ability to adapt the potential travel modes to the daily changing situation depending on traveler's needs. We see that individuality is particularly related to new and multimodal travel modes. As new technological opportunities enable travelers to customize and mix travel modes through smartphone apps or web interfaces, this new dimension will lead to significant opportunities for the future design of urban travel. This finding calls for more research on ways to customize available travel modes to customer requirements. As the individuality factor comprised innovativeness and service-degree, new mobility providers should think about new business models that reflect travelers' requirements from a utility- and service-based perspective (Firnkorn and Müller, 2012; Storbacka et al., 2012). In particular, new opportunities of providing interfaces of customized devices such as smartphones with collective travel modes such as shared cars should be considered in future studies (Wang and Fesenmaier, 2013).

d) Advantages of multimodal travel modes: Multimodal travel has complementarity comparative advantages. While multimodal travel options might be more costly but offer more privacy than 
public transport (also regarding environmental aspects) and are less autonomous and cheaper than the private car, they level out the weaknesses of either single approach. Therefore, by combining travel modes with different advantages and disadvantages, multimodal travel modes seem to offer composed hybrid travel modes. As multimodal travel modes are perceived as significantly better when compared to public transport and the private car regarding individuality, these hybrid travel modes gain unique advantage by a high situational and personal adaptability for urban travelers (Susilo and Cats, 2014).

e) Ideal values of determinants of travel mode choice: Finally, we find that travelers individual ideal travel modes do not necessarily maximize all determinants. For example for privacy and long distance capability, the high values for the car significantly exceed the levels that are perceived as ideal. This speaks against linear "the more the better" thinking and highlights the need for further research on nonlinear effects and interaction effects of the determinants. Interestingly, the comparison of real and ideal modes also shows that the expected level of stresslessness as well as all cost determinants is not fulfilled by either travel mode. This emphasizes latent customer needs to be addressed.

\subsection{Managerial implications}

Our study provides relevant implications for providers of innovative multimodal travel options, policy-makers and transportation planners, particularly for the design of new multimodal travel options. These complementary travel modes should be explicitly designed in such a way as to overcome the remaining limitations in comparison to monomodal travel modes such as the private car. A special focus should be applied to positioning and new product development.

Based on a categorical principal component analysis we visualized the travel modes and the determinants of mode choice in a joint perceptual multi-dimensional space (Figure 4). The resulting collective cognitive maps visualize the relative mental positions of the travel modes and the determinants of mode choice (Wright, 2004). Hence, strategies for a mental repositioning of 
specific travel modes can be developed. The cognitive map on the left-hand side of Figure 4 comprises the dimensions of affect, convenience and cost. Ideal travel modes (area A) are positioned close to the key affective determinants of privacy, flexible route choice, autonomy etc. However, they are relatively distant from monetary and environmental costs. Multimodal travel modes (area B) are in very close proximity to these ideal travel modes. Providers of innovative multimodal travel offers should emphasize the determinants associated with their current position. Affective determinants of mode choice, privacy, autonomy and stresslessness are the result of an individual interpretation and feeling related to the design parameters of travel modes. Hence, their perception by urban travelers can be influenced. Service providers of innovative multimodal travel options, policy-makers and transportation planners can emphasize the autonomy and privacy of multimodal travel options. This could be done for example by marketing campaigns that emphasize the situational control and independence from unreliable public services while potentially being able to use a wide array of travel modes. Furthermore, the positive environmental effect of collective use of certain modes and a combination of different modes should be highlighted to travelers. Transparent information about carbon dioxide emissions (e.g. by contrasting these to different combinations of travel modes in an app) might help to emphasize the real costs of a travel mode choice to travelers. Furthermore, providers of public transport (area C) and car-based travel modes (area D) can try to reposition their travel modes by using innovative approaches. Product and service design can find solutions to increase privacy and autonomy in public transport (e.g. by providing silent areas in trams or supporting ICT services). Car manufacturers, taxi services and rental car agencies are advised to reduce the mental costs associated with the car by improving environmental friendliness (e.g. e-mobility) or business models for a higher capacity utilization (e.g. collective consumption).

The collective cognitive map on the right-hand side of figure 4 visualizes the remaining dimensions of stress, innovation and flexibility. Ideal travel modes (area E) are positioned in close proximity to the determinants of low stress and being fast. Multimodal travel modes (area 
F) are perceived as innovative, delivering a high service degree and allowing for situational adaption. Nevertheless, just underlining their innovativeness might be insufficient. In order to close the gap to the ideal travel modes, speed should be increased and stress reduced. The first calls for seamless interfaces between travel modes in multimodal travel (Beirão and Sarsfield Cabral, 2007). Currently, urban travelers perceive multimodal travel options, especially the smartphone-based offer, as rather difficult to use as compared to other mono modes and the ideal mode. Stresslessness can be achieved by an increased ease of use through optimization of the functionality and reliability of offers. Furthermore, providers of multimodal travel options should emphasize the existing customer benefits regarding speed (e.g. avoiding traffic jams during the rush hour) and stresslessness (e.g. opportunities for using the tram or providing bike- or carsharing when public transport is not available). The private car does not outperform public transport in terms of perceived stress and time efficiency (area G). Both modes are perceived as stressful and are associated with a low service degree and situational adaptivity. Hence, the individuality of public systems (shared cars, subway seats) should be increased by interfaces with smartphones. By the provision of services and especially by a high degree of innovativeness, providers of multimodal travel options differentiate new travel modes. New offers could fulfill heterogeneous travelers' needs in terms of varying lifestyles, type of journey and situational context (Beirão and Sarsfield Cabral, 2007). Integrated and flexible offerings with varying numbers of specific travel modes could address the needs of people with different preferences.

\subsection{Limitations and Outlook}

As usual, our study is not without limitations. First, although our sample includes public transport and private car users, we did not consider different user characteristics. According to the results of Jensen (1999) who identifies six different traveler types, it could be expected that different user groups will have varying preferences regarding the importance of the determinants. Passionate car drivers may be more concerned with affective or symbolic aspects than everyday 
car drivers or public transport users. Not explicitly considering different traveler types (e.g. leisure time car-drivers) could be the reason that symbolic determinants of travel mode choice were not identified (Hiscock et al., 2002). As individual differences might bias our results, further research should assess the consistence of our findings for different groups.

Second, our interviewees were all residents of the metropolitan region of Hamburg. Although Hamburg can be considered as a typical example of a large international city that faces the current challenges regarding mobility in high density areas, generalizability of our findings could be questioned. In particular, perception of various travel modes might differ for people traveling in alternative contextual conditions (e.g. rural areas, smaller cities) in which the advantages and disadvantages of travel modes change (e.g. parking space is less costly and public transport not as well established). We encourage future studies to replicate our analysis in other travel contexts. Third, we did not measure an objective performance variable but relied on mean comparisons of existing ideal travel modes. This limitation is closely related to the exploratory nature of our method. Future research could make use of our results for large-scale survey studies in order to relate key determinants of travel mode choice to real selections of multimodal travel options. 


\section{References}

Anable, J., Gatersleben, B. (2005) All work and no play? The role of instrumental and affective factors in work and leisure journeys by different travel modes. Transportation Research Part A: Policy and Practice 39, 163-181.

Arentze, T.A., Molin, E.J. (2013) Travelers' preferences in multimodal networks: design and results of a comprehensive series of choice experiments. Transportation Research Part A: Policy and Practice 58, 15-28.

Beirão, G., Sarsfield Cabral, J. (2007) Understanding attitudes towards public transport and private car: A qualitative study. Transport Policy 14, 478-489.

Ben-Elia, E., Ettema, D. (2011) Rewarding rush-hour avoidance: A study of commuters' travel behavior. Transportation Research Part A: Policy and Practice 45, 567-582.

Buys, L., Miller, E. (2011) Conceptualising convenience: Transportation practices and perceptions of inner-urban high density residents in Brisbane, Australia. Transport Policy 18, 289-297.

Cairns, S., Harmer, C., Hopkin, J., Skippon, S. (2014) Sociological perspectives on travel and mobilities: A review. Transportation Research Part a-Policy and Practice 63, 107-117.

Chatman, D.G. (2008) Deconstructing development density: Quality, quantity and price effects on household nonwork travel. Transportation Research Part A: Policy and Practice 42, 1008-1030.

de Palma, A., Picard, N. (2005) Route choice decision under travel time uncertainty. Transportation Research Part a-Policy and Practice 39, 295-324.

Dunn, W.N., Cahill, A.G., Dukes, M.J., Gomsberg, A. (1986) The policy grid: A cognitive methodology for assessing policy dynamics. Policy Analysis: Perspectives, Concepts, and Methods ed Dunn, W.N. JAI Press, Greenwich, pp. 355-375.

Easterby-Smith, M., Thorpe, R., Holman, D. (1996) Using repertory grids in management. Journal of European Industrial Training 20, 3-30.

Ellaway, A., Macintyre, S., Hiscock, R., Kearns, A. (2003) In the driving seat: psychosocial benefits from private motor vehicle transport compared to public transport. Transportation Research Part F: Traffic Psychology and Behaviour 6, 217-231.

Eriksson, L., Garvill, J., Nordlund, A.M. (2008) Acceptability of single and combined transport policy measures: The importance of environmental and policy specific beliefs. Transportation Research Part A: Policy and Practice 42, 1117-1128.

Fernández-Heredia, Á., Monzon, A., Jara-Díaz, S. (2014) Understanding cyclists’ perceptions, keys for a successful bicycle promotion. Transportation research part A: policy and practice 63, 1-11.

Firnkorn, J., Müller, M. (2012) Selling Mobility instead of Cars: New Business Strategies of Automakers and the Impact on Private Vehicle Holding. Business Strategy and the Environment 21, 264-280.

Fransella, F., Bannister, D. (1977) A manual for repertory grid technique. Academic Press, London et al.

Friman, M., Edvardsson, B., Gärling, T. (2001) Frequency of negative critical incidents and satisfaction with public transport services. I. Journal of Retailing and Consumer Services 8, 95-104.

Gardner, B., Abraham, C. (2007) What drives car use? A grounded theory analysis of commuters' reasons for driving. Transportation Research Part F: Traffic Psychology and Behaviour 10, 187-200.

Gardner, B., Abraham, C. (2008) Psychological correlates of car use: A meta-analysis. Transportation research part F: traffic psychology and behaviour 11, 300-311.

Gatersleben, B., Uzzell, D. (2007) Affective Appraisals of the Daily Commute Comparing Perceptions of Drivers, Cyclists, Walkers, and Users of Public Transport. Environment and Behavior 39, 416-431.

Goffin, K., Koners, U. (2011) Tacit Knowledge, Lessons Learnt, and New Product Development. J. Prod. Inno. Manage. 28, 300-318.

Goffin, K., Lemke, F., Szwejczewski, M. (2006) An exploratory study of 'close' supplier-manufacturer relationships. J. Oper. Manage. 24, 189-209.

Grewal, R., Mehta, R., Kardes, F.R. (2000) The role of the social-identity function of attitudes in consumer innovativeness and opinion leadership. Journal of Economic Psychology 21, 233-252.

Grotenhuis, J.-W., Wiegmans, B.W., Rietveld, P. (2007) The desired quality of integrated multimodal travel information in public transport: Customer needs for time and effort savings. Transport Policy 14, 27-38.

Guiver, J.W. (2007) Modal talk: discourse analysis of how people talk about bus and car travel. Transportation Research Part A: Policy and Practice 41, 233-248.

Habib, K.N., Sasic, A., Weis, C., Axhausen, K. (2013) Investigating the nonlinear relationship between transportation system performance and daily activity-travel scheduling behaviour. Transportation Research Part aPolicy and Practice 49, 342-357.

Hagman, O. (2003) Mobilizing meanings of mobility: car users' constructions of the goods and bads of car use. Transportation Research Part D: Transport and Environment 8, 1-9.

Hine, J., Scott, J. (2000) Seamless, accessible travel: users' views of the public transport journey and interchange. Transport Policy 7, 217-226. 
Hiscock, R., Macintyre, S., Kearns, A., Ellaway, A. (2002) Means of transport and ontological security: Do cars provide psycho-social benefits to their users? Transportation Research Part D: Transport and Environment 7, 119135.

Honey, P. (1979) The repertory grid in action. Industrial and Commercial Training 11, 452-459.

Jankovicz, D. (2004) The easy guide to repertory grids. Wiley, Chichester.

Jensen, M. (1999) Passion and heart in transport—a sociological analysis on transport behaviour. Transport Policy 6, 19-33.

Johansson, M., Heldt, T., Johansson, P. (2006) The effects of attitudes and personality traits on mode choice. Transportation Research Part A 40, 507.

Kelly, G. (1955) The psychology of personal constructs. Norton, New York.

Kenworthy, J.R., Laube, F.B. (1999) Patterns of automobile dependence in cities: an international overview of key physical and economic dimensions with some implications for urban policy. Transportation Research Part A: Policy and Practice 33, 691-723.

Khattak, A.J., De Palma, A. (1997) The impact of adverse weather conditions on the propensity to change travel decisions: a survey of Brussels commuters. Transportation Research Part A: Policy and Practice 31, 181-203.

Kramers, A. (2014) Designing next generation multimodal traveler information systems to support sustainabilityoriented decisions. Environmental Modelling \& Software 56, 83-93.

Kuhnimhof, T., Armoogum, J., Buehler, R., Dargay, J., Denstadli, J.M., Yamamoto, T. (2012) Men shape a downward trend in car use among young adults—evidence from six industrialized countries. Transport Reviews 32, 761-779.

Lerner, W. (2011) The Future of Urban Mobility: Towards networked, multimodal cities of 2050.

Lois, D., López-Sáez, M. (2009) The relationship between instrumental, symbolic and affective factors as predictors of car use: A structural equation modeling approach. Transportation Research Part A: Policy and Practice 43, 790799.

Mann, E., Abraham, C. (2006) The role of affect in UK commuters' travel mode choices: An interpretative phenomenological analysis. British Journal of Psychology 97, 155-176.

Marquet, O., Miralles-Guasch, C. (2014) Walking short distances. The socioeconomic drivers for the use of proximity in everyday mobility in Barcelona. Transportation Research Part a-Policy and Practice 70, $210-222$.

Murtagh, N., Gatersleben, B., Uzzell, D. (2012) Multiple identities and travel mode choice for regular journeys. Transportation research part F: traffic psychology and behaviour 15, 514-524.

Nilsson, M., Küller, R. (2000) Travel behaviour and environmental concern. Transportation Research Part D: Transport and Environment 5, 211-234.

Pooley, C.G., Turnbull, J. (2000) Modal choice and modal change: the journey to work in Britain since 1890. Journal of Transport Geography 8, 11-24.

Redman, L., Friman, M., Garling, T., Hartig, T. (2013) Quality attributes of public transport that attract car users: A research review. Transport Policy 25, 119-127.

Steg, L. (2003) Can public transport compete with the private car? IATSS RESEARCH 27, 27.

Steg, L. (2005) Car use: lust and must. Instrumental, symbolic and affective motives for car use. Transportation Research Part A: Policy and Practice 39, 147-162.

Storbacka, K., Frow, P., Nenonen, S., Payne, A. (2012) Designing business models for value co-creation. Review of Marketing Research 9, 51-78.

Stradling, S.G. (2002) Transport user needs and marketing public transport. Proceedings of the ICE-Municipal Engineer 151, 23-28.

Su, Q. (2010) Travel demand in the US urban areas: A system dynamic panel data approach. Transportation Research Part A: Policy and Practice 44, 110-117.

Susilo, Y.O., Cats, O. (2014) Exploring key determinants of travel satisfaction for multi-modal trips by different traveler groups. Transportation Research Part a-Policy and Practice 67, 366-380.

Tan, F.B., Hunter, M.G. (2002) The repertory grid technique: A method for the study of cognition in information systems. Mis Quarterly, 39-57.

Taylor, B.D., Miller, D., Iseki, H., Fink, C. (2009) Nature and/or nurture? Analyzing the determinants of transit ridership across US urbanized areas. Transportation Research Part A: Policy and Practice 43, 60-77.

Van Exel, N., Rietveld, P. (2009) Could you also have made this trip by another mode? An investigation of perceived travel possibilities of car and train travellers on the main travel corridors to the city of Amsterdam, The Netherlands. Transportation Research Part A: Policy and Practice 43, 374-385.

Verplanken, B., Aarts, H. (1999) Habit, attitude, and planned behaviour: is habit an empty construct or an interesting case of goal-directed automaticity? European review of social psychology 10, 101-134.

Vij, A., Carrel, A., Walker, J.L. (2013) Incorporating the influence of latent modal preferences on travel mode choice behavior. Transportation Research Part a-Policy and Practice 54, 164-178.

Wang, D., Fesenmaier, D.R. (2013) Transforming the travel experience: The use of smartphones for travel. Springer. Wright, R.P. (2004) Mapping Cognitions to Better Understand Attitudinal and Behavioral Responses in Appraisal Research. Journal of Organizational Behavior 25, 339-374. 
TABLE 1

Summary of determinants of travel mode choice in previous research

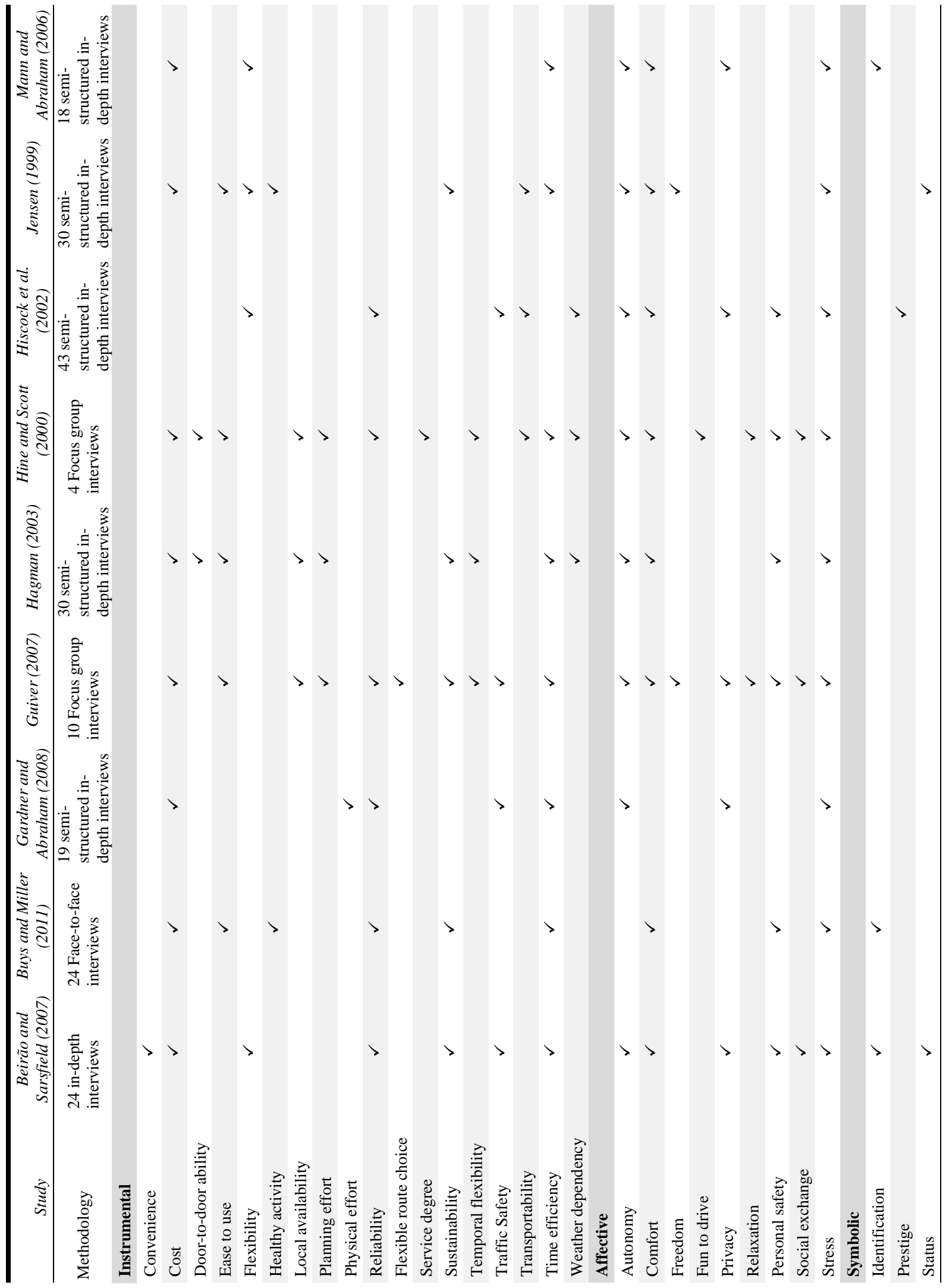


TABLE 2

Identified determinants of travel mode choice

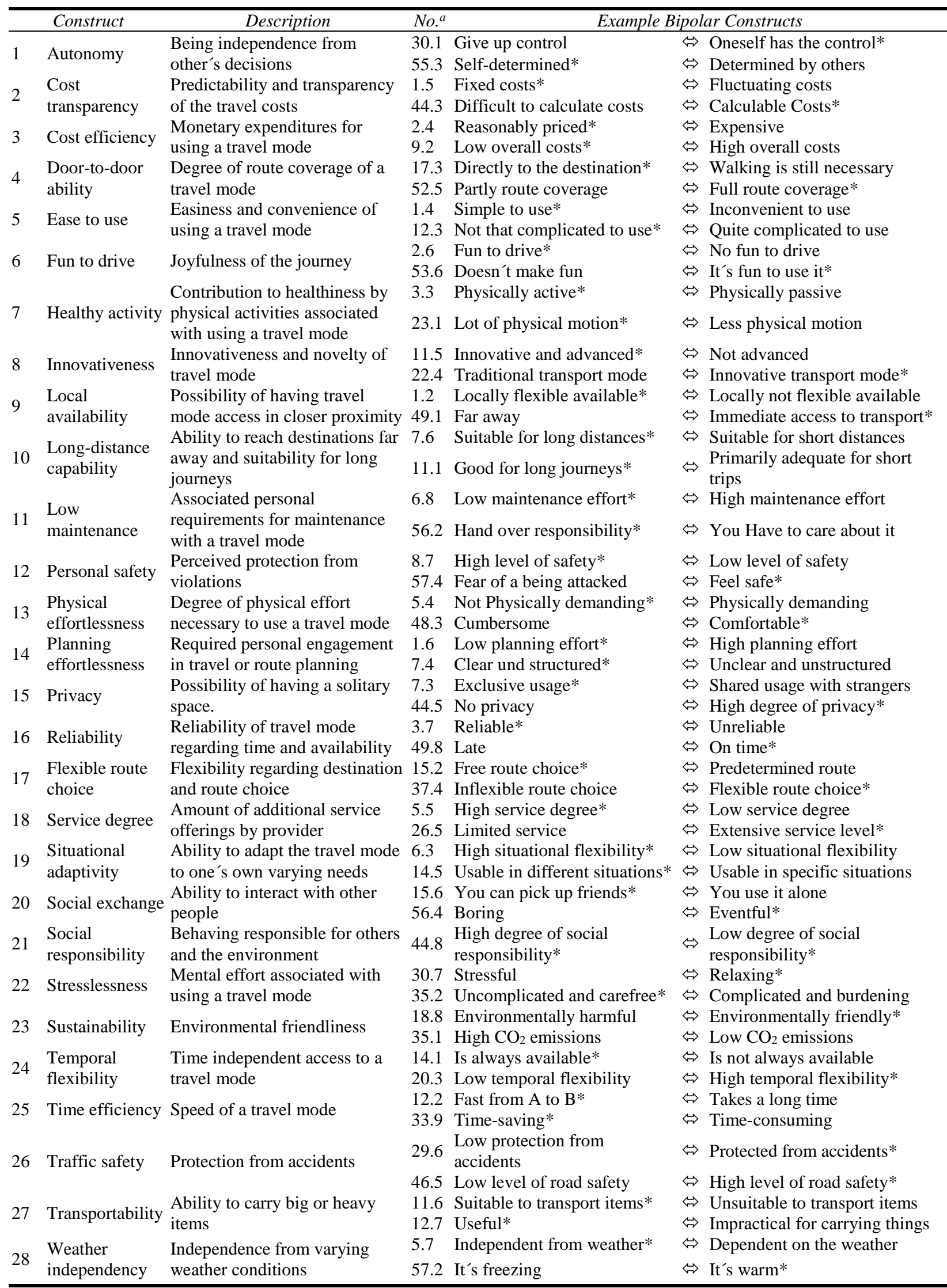

Note: Asterisks mark the perceived positive pole from the perspective of the participant; a) First number indicates the number of the respondent, the second number indicates the number of the construct mentioned 
TABLE 3

Obliquely rotated principal component analysis of the determinants of travel mode choice

\begin{tabular}{|c|c|c|c|c|c|c|}
\hline Determinant Factor & Affect & Convenience & Stress & Individuality & Cost & Flexibility \\
\hline Autonomy & .93 & & & & & \\
\hline Fun to drive & .92 & & & & & \\
\hline Personal safety & .90 & -.41 & & & & \\
\hline Privacy & .88 & & & & & \\
\hline $\begin{array}{l}\text { Planning } \\
\text { effortlessness }\end{array}$ & -.75 & & & & & -.64 \\
\hline Flexible route choice & .69 & & & & -.40 & \\
\hline $\begin{array}{l}\text { Physical } \\
\text { effortlessness }\end{array}$ & & -.97 & & & & \\
\hline $\begin{array}{l}\text { Weather } \\
\text { independency }\end{array}$ & & -.93 & & & & \\
\hline Healthy activity & & .88 & & & & \\
\hline Traffic safety & & -.85 & & & .64 & \\
\hline Transportability & .48 & -.61 & & & & \\
\hline Time efficiency & & -.60 & & .43 & & -.48 \\
\hline $\begin{array}{l}\text { Long-distance } \\
\text { capability }\end{array}$ & & -.46 & -.84 & & & \\
\hline Stresslessness & & & .66 & & & -.41 \\
\hline Low maintenance & -.41 & & .59 & & & .44 \\
\hline Situational adaptivity & & & & .96 & & \\
\hline Innovativeness & & & & .91 & & \\
\hline Service degree & & & & .73 & & \\
\hline Cost transparency & & & & & .74 & \\
\hline Cost efficiency & & .50 & & & .64 & \\
\hline Sustainability & & .51 & & & .59 & \\
\hline Door-to-door ability & .44 & & & & -.50 & -.41 \\
\hline Ease to use & & & & & & -.89 \\
\hline Local availability & & & & & & -.83 \\
\hline Temporal flexibility & .46 & & & & & -.69 \\
\hline Reliability & .42 & & & & .47 & -.66 \\
\hline
\end{tabular}

Note: Constructs that were mentioned less than 4 times were not considered for the principle component analysis. Factor loadings below .4 are not displayed. 
TABLE 4

Key determinants of travel mode choice

\begin{tabular}{|c|c|c|c|}
\hline Construct & Factor & Frequency & $\begin{array}{c}\text { Average Normalized } \\
\text { Variability (\%) }\end{array}$ \\
\hline Cost efficiency & Cost & 37 & 15.13 \\
\hline Time efficiency & Convenience & 36 & 12.80 \\
\hline Temporal flexibility & Flexibility & 35 & 14.49 \\
\hline Privacy & Affect & 22 & 25.41 \\
\hline Flexible route choice & Affect & 20 & 18.11 \\
\hline Local availability & Flexibility & 20 & 15.74 \\
\hline Weather independency & Convenience & 17 & 15.73 \\
\hline Autonomy & Affect & 15 & 20.28 \\
\hline Situational adaptivity & Individuality & 14 & 15.48 \\
\hline Reliability & Flexibility & 14 & 10.58 \\
\hline Sustainability & Cost & 13 & 19.86 \\
\hline Physical effortlessness & Convenience & 13 & 15.48 \\
\hline Stresslessness & Stress & 12 & 17.07 \\
\hline Ease to use & Flexibility & 12 & 14.94 \\
\hline Door-to-door ability & Cost & 12 & 12.31 \\
\hline Long-distance capability & Stress & 11 & 13.77 \\
\hline Transportability & Convenience & 9 & 19.57 \\
\hline Personal safety & Affect & 8 & 15.35 \\
\hline Traffic safety & Convenience & 7 & 12.05 \\
\hline Service degree & Individuality & 6 & 19.57 \\
\hline Fun to drive & Affect & 6 & 18.94 \\
\hline Healthy activity & Convenience & 6 & 18.08 \\
\hline Innovativeness & Individuality & 5 & 23.75 \\
\hline Low maintenance & Stress & 5 & 19.19 \\
\hline Cost transparency & Cost & 4 & 17.04 \\
\hline Planning effortlessness & Affect & 4 & 13.86 \\
\hline Social exchange & Cost & 2 & 27.84 \\
\hline \multirow[t]{2}{*}{ Social responsibility } & Convenience & 1 & 25.84 \\
\hline & Mean & 13.07 & 16.39 \\
\hline
\end{tabular}

Note: Determinants mentioned by at least $20 \%$ of the respondents and a variability greater than the average are highlighted. 
FIGURE 1

Classification of travel modes

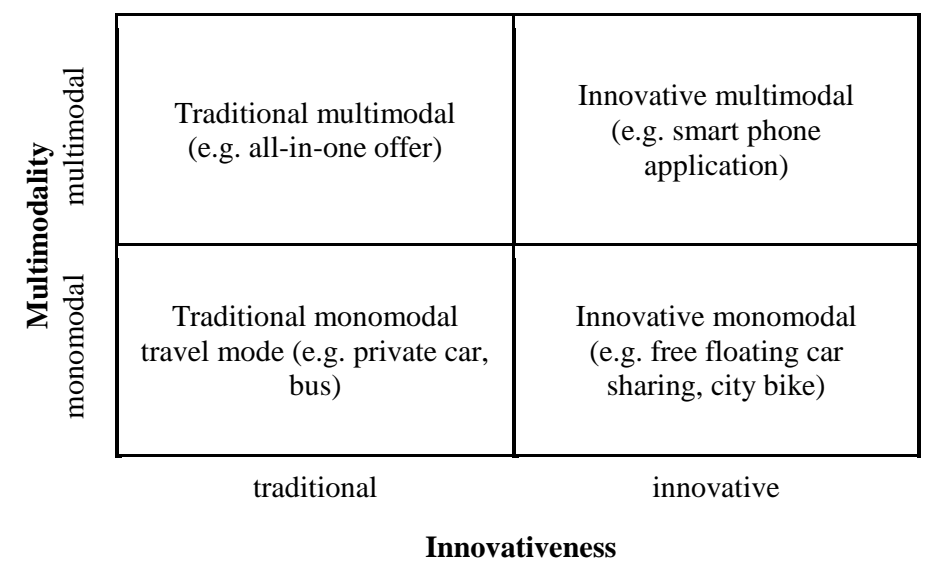


FIGURE 2

Affective and individual determinants of travel mode choice

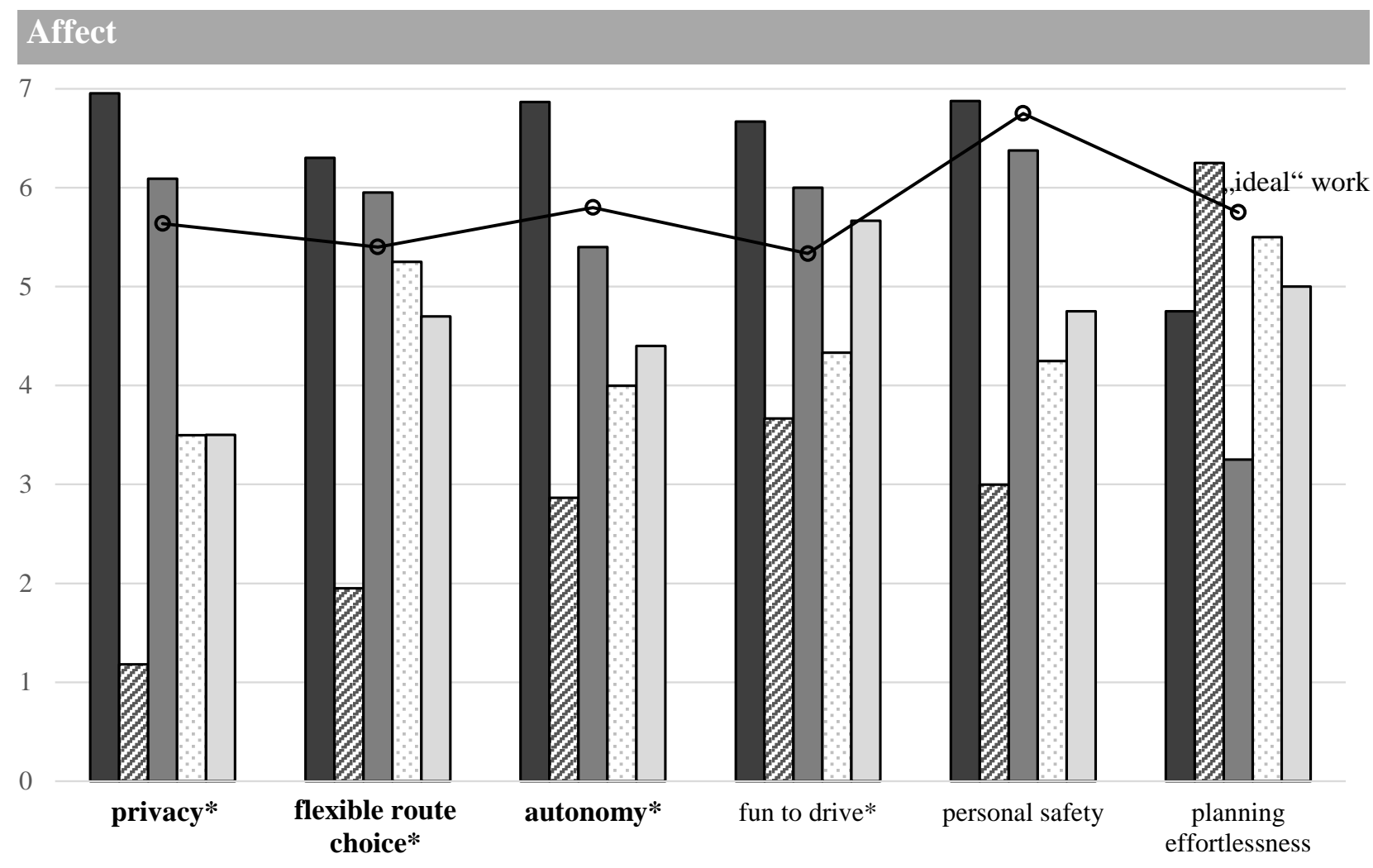

Stress Individuality

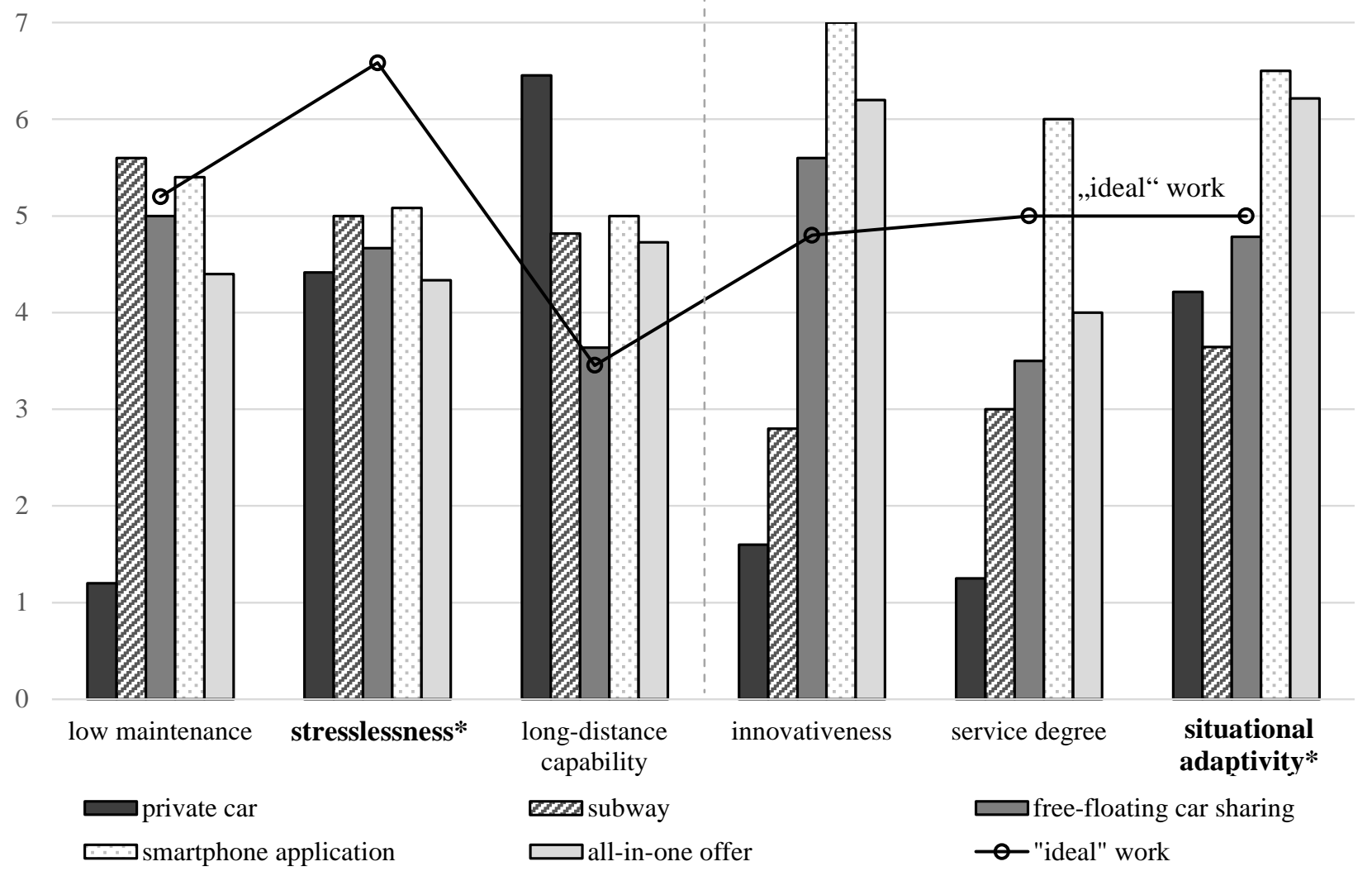

Note: Constructs in bold type were mentioned by at least $20 \%$ of the respondents. Asterisks indicate constructs with an ANV above the average. 
FIGURE 3

Instrumental determinants of travel mode choice
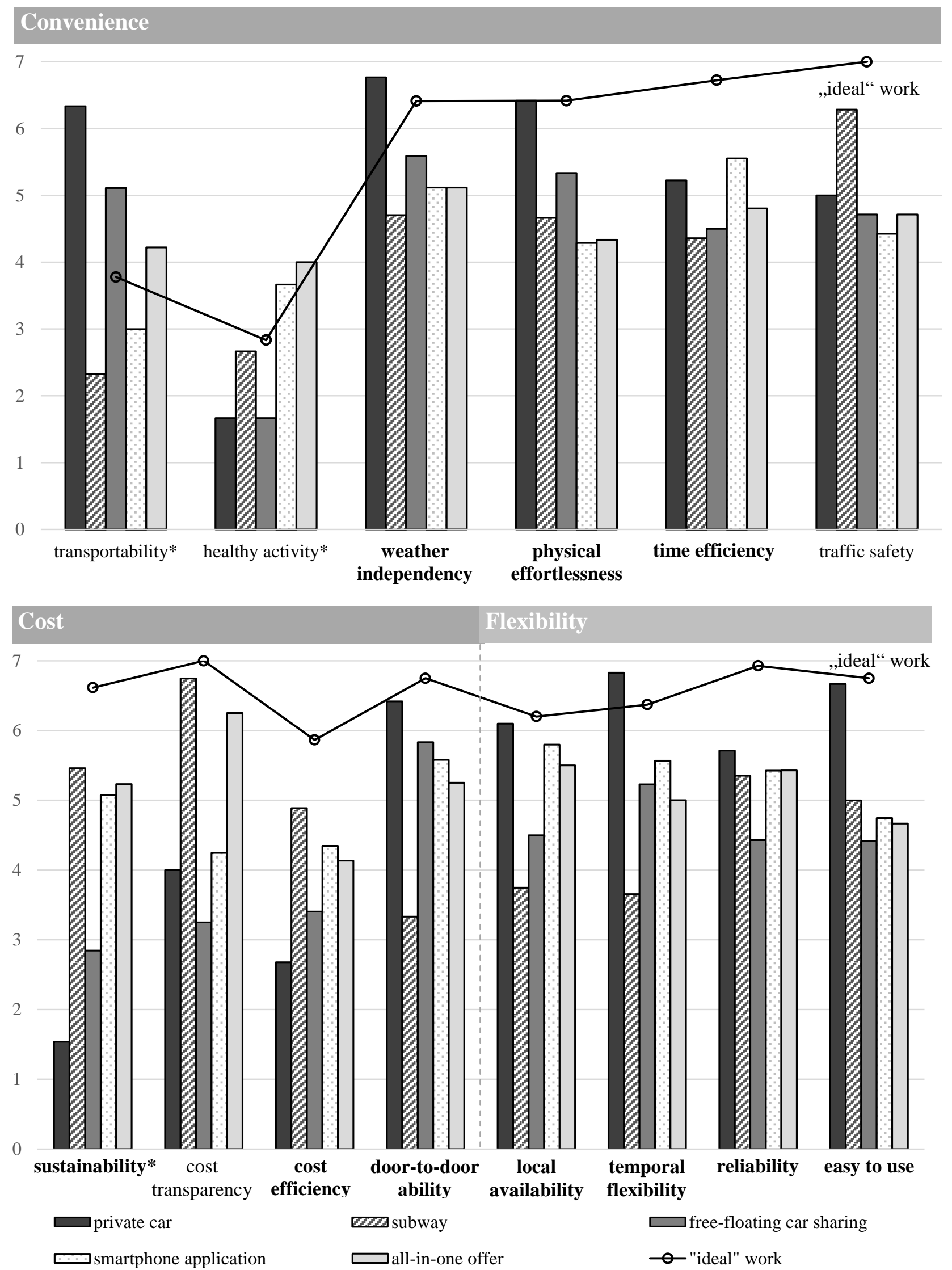

Note: Constructs in bold type were mentioned by at least $20 \%$ of the respondents. Asterisks indicate constructs with an ANV above the average. 
FIGURE 4

Collective cognitive maps of urban travelers

Principle components affect, convenience and cost

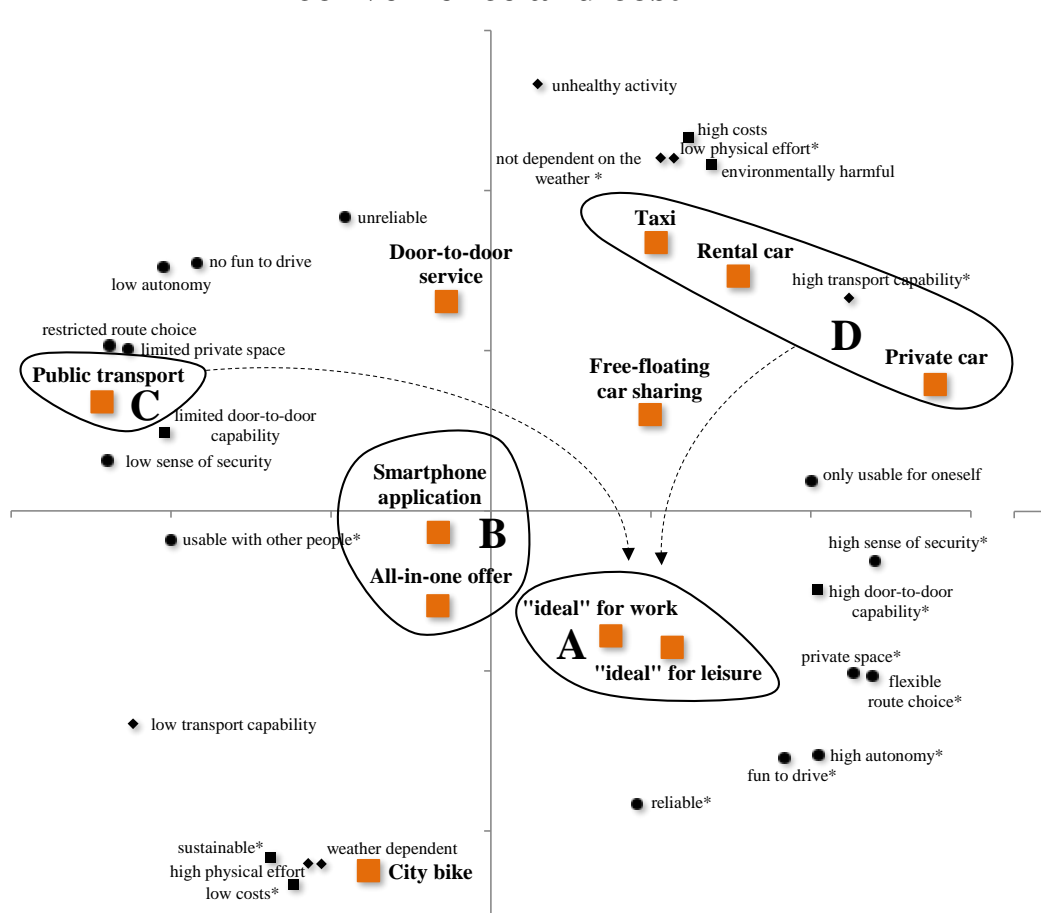

- Affect

- Convenience

- Cost<smiles>[CH]1CCC1</smiles>

Principle components stress, innovation and flexibility

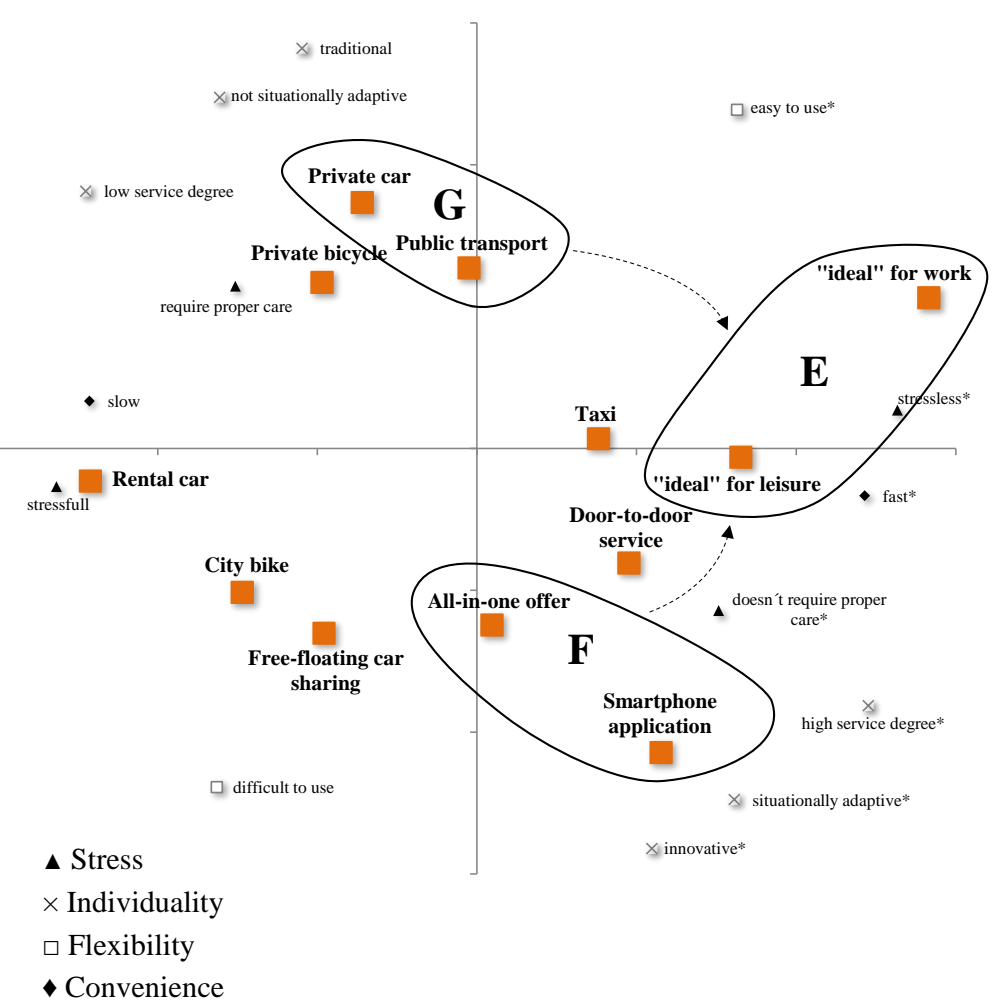

Note: The asterisks indicate the positive pole.

Each determinant of travel mode choice is represented by vector lines with opposing construct poles. The higher the distance from the center, the higher the loading on the underlying principle component ( $\mathrm{x}$ - and $\mathrm{y}$-axes). Because of a lack of interpretability, constructs with a factor loading $<1$ are not visualized. 


\section{Appendix}

Table A.1

Travel modes (elements) used for the repertory grid interviews

\begin{tabular}{|c|c|c|c|c|}
\hline $\begin{array}{l}\text { Ele- } \\
\text { ment }\end{array}$ & Travel mode & Description & Type & $\begin{array}{l}\text { Public } \\
\text { vs. } \\
\text { private }\end{array}$ \\
\hline $\mathbf{E}_{1}$ & Private car & Privately owned car & $\begin{array}{l}\text { traditional- } \\
\text { monomodal }\end{array}$ & private \\
\hline $\mathbf{E}_{2}$ & Private bicycle & Privately owned bicycle & $\begin{array}{l}\text { traditional- } \\
\text { monomodal }\end{array}$ & private \\
\hline $\mathbf{E}_{3}$ & Taxi & Traditional taxi service & $\begin{array}{l}\text { traditional- } \\
\text { monomodal }\end{array}$ & private \\
\hline $\mathbf{E}_{4}$ & Rental car & $\begin{array}{l}\text { Traditional rental car that can be picked up and dropped off in } \\
\text { rental car stations }\end{array}$ & $\begin{array}{l}\text { traditional- } \\
\text { monomodal }\end{array}$ & private \\
\hline $\mathbf{E}_{5}$ & City bike & $\begin{array}{l}\text { Rental bikes that can be spontaneously and independently rent } \\
\text { by registered users at specific pick-up points in urban areas } \\
\text { via terminals or mobile applications }\end{array}$ & $\begin{array}{l}\text { innovative- } \\
\text { monomodal }\end{array}$ & private \\
\hline $\mathbf{E}_{6}$ & $\begin{array}{l}\text { Free-floating } \\
\text { car sharing }\end{array}$ & $\begin{array}{l}\text { Rental cars that can be spontaneously and independently rent } \\
\text { by registered users in urban areas via terminals or mobile } \\
\text { applications (e.g. Car2Go) }\end{array}$ & $\begin{array}{l}\text { innovative- } \\
\text { monomodal }\end{array}$ & private \\
\hline $\mathbf{E}_{7}$ & Bus & Public buses & $\begin{array}{l}\text { traditional- } \\
\text { monomodal }\end{array}$ & public \\
\hline E8 & Subway & Public subways & $\begin{array}{l}\text { traditional- } \\
\text { monomodal }\end{array}$ & public \\
\hline E9 & Tram & Public trams & $\begin{array}{l}\text { traditional- } \\
\text { monomodal }\end{array}$ & public \\
\hline E10 & All-in-one offer & $\begin{array}{l}\text { The all-in-one allows self-selected multimodal travel based } \\
\text { on a travel flat rate. The offer combines unlimited intra city } \\
\text { public transport and the use of city bikes for up to } 240 \\
\text { minutes per day and free-floating car sharing for up to } 90 \\
\text { minutes per day on a monthly rate. }\end{array}$ & $\begin{array}{l}\text { traditional } \\
\text { multimodal }\end{array}$ & both \\
\hline $\mathbf{E}_{11}$ & $\begin{array}{l}\text { Smartphone } \\
\text { application for } \\
\text { multimodal } \\
\text { travel }\end{array}$ & $\begin{array}{l}\text { Mobile application that automatically searches for an optimal } \\
\text { combination of public urban travel modes including city bikes } \\
\text { and cars in order to reach a destination. The current traffic } \\
\text { situation is flexibly considered in travel plans. }\end{array}$ & $\begin{array}{l}\text { innovative- } \\
\text { multimodal }\end{array}$ & both \\
\hline $\mathbf{E}_{12}$ & $\begin{array}{l}\text { Door-to-door } \\
\text { service }\end{array}$ & $\begin{array}{l}\text { The door-to-door service covers unlimited intra city public } \\
\text { transport. Furthermore, the service includes reasonable direct } \\
\text { transfer from the station to the final destination. Options are } \\
\text { selected depending on availability and preferences. }\end{array}$ & $\begin{array}{l}\text { innovative- } \\
\text { multimodal }\end{array}$ & both \\
\hline $\mathbf{E}_{13}$ & $\begin{array}{l}\text { „Ideal“ for way } \\
\text { to work }\end{array}$ & Perceived ideal mobility mode for the way to work & ideal & \\
\hline $\mathbf{E}_{14}$ & $\begin{array}{l}\text { „Ideal“ for } \\
\text { leisure time }\end{array}$ & Perceived ideal mobility mode for leisure time travel. & ideal & \\
\hline
\end{tabular}




\section{Table A.2}

\section{Super grid of the elicited determinants of travel mode choice}

氜 苋䓪

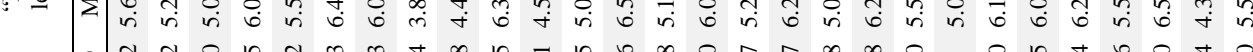

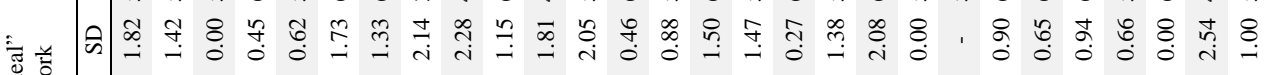

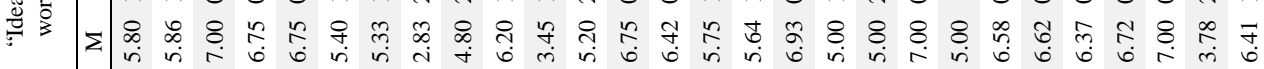

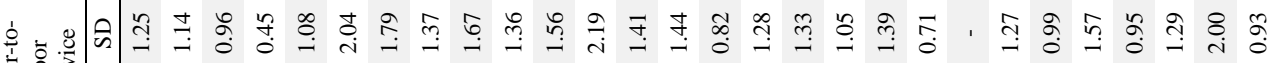

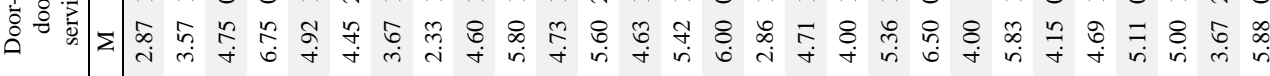

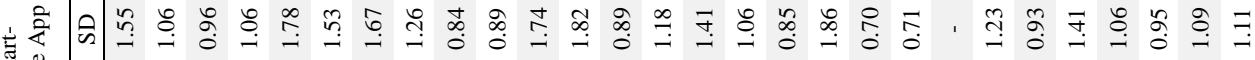

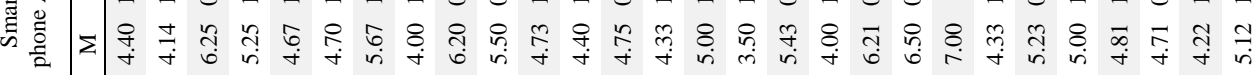

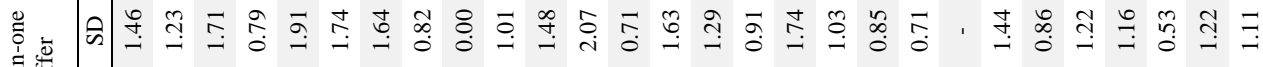

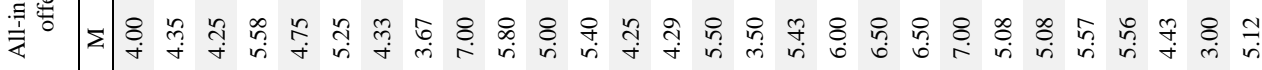
E की

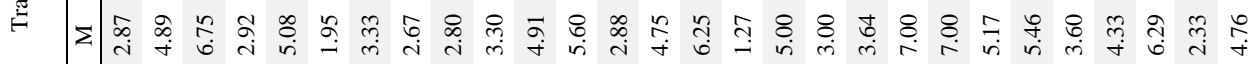
क की

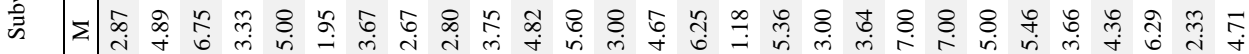

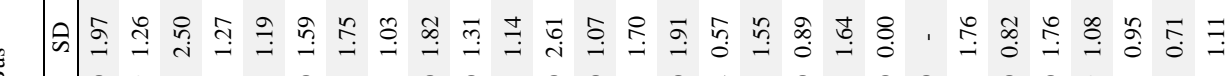

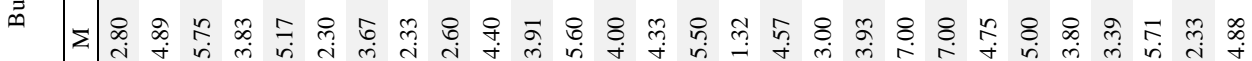

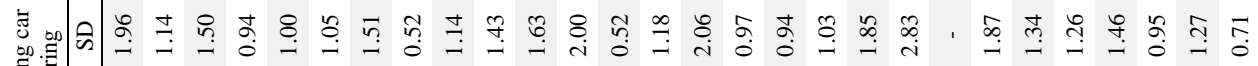

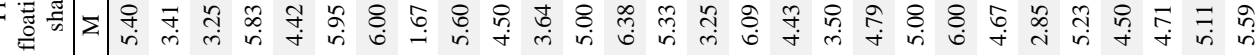
芦 की

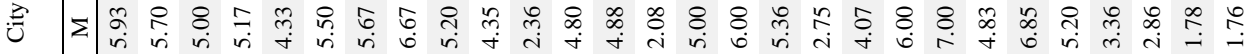

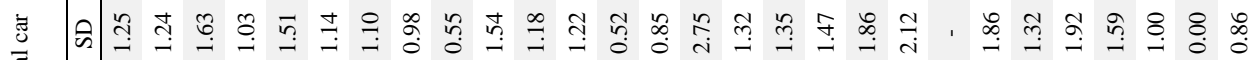

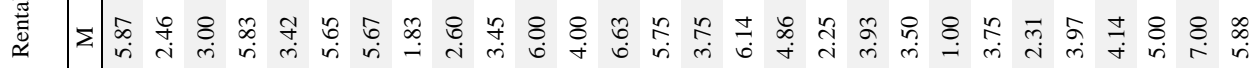

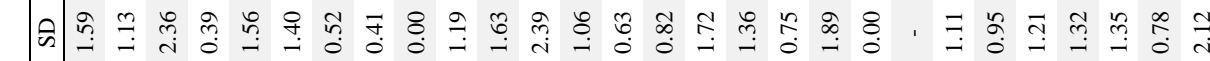

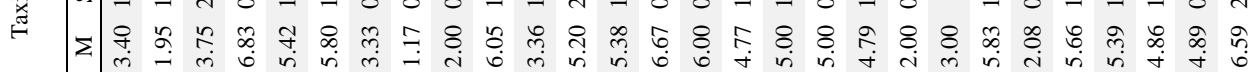

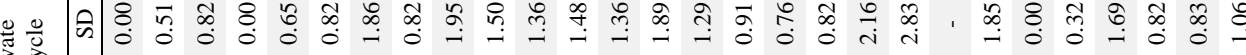

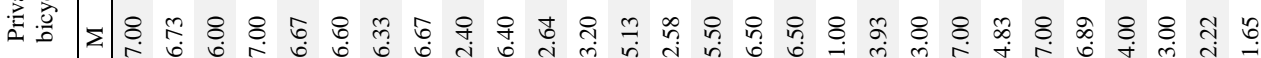
氜 कि

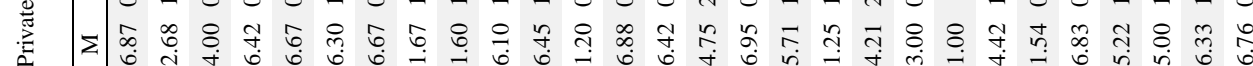

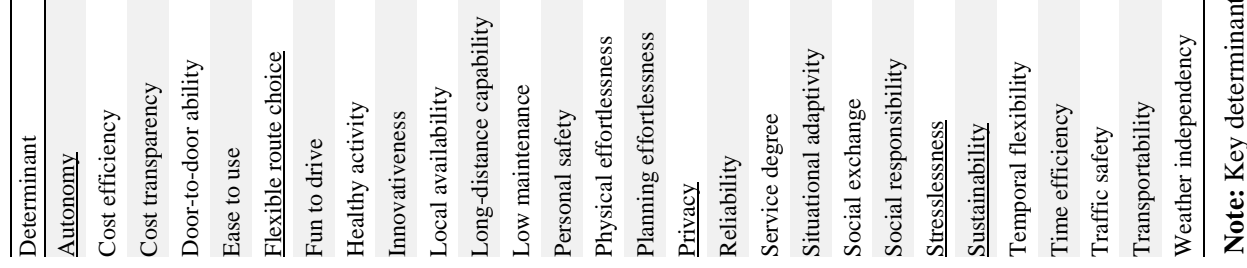


Table A.3

One-Way-Anova (Post-Hoc-Tests)

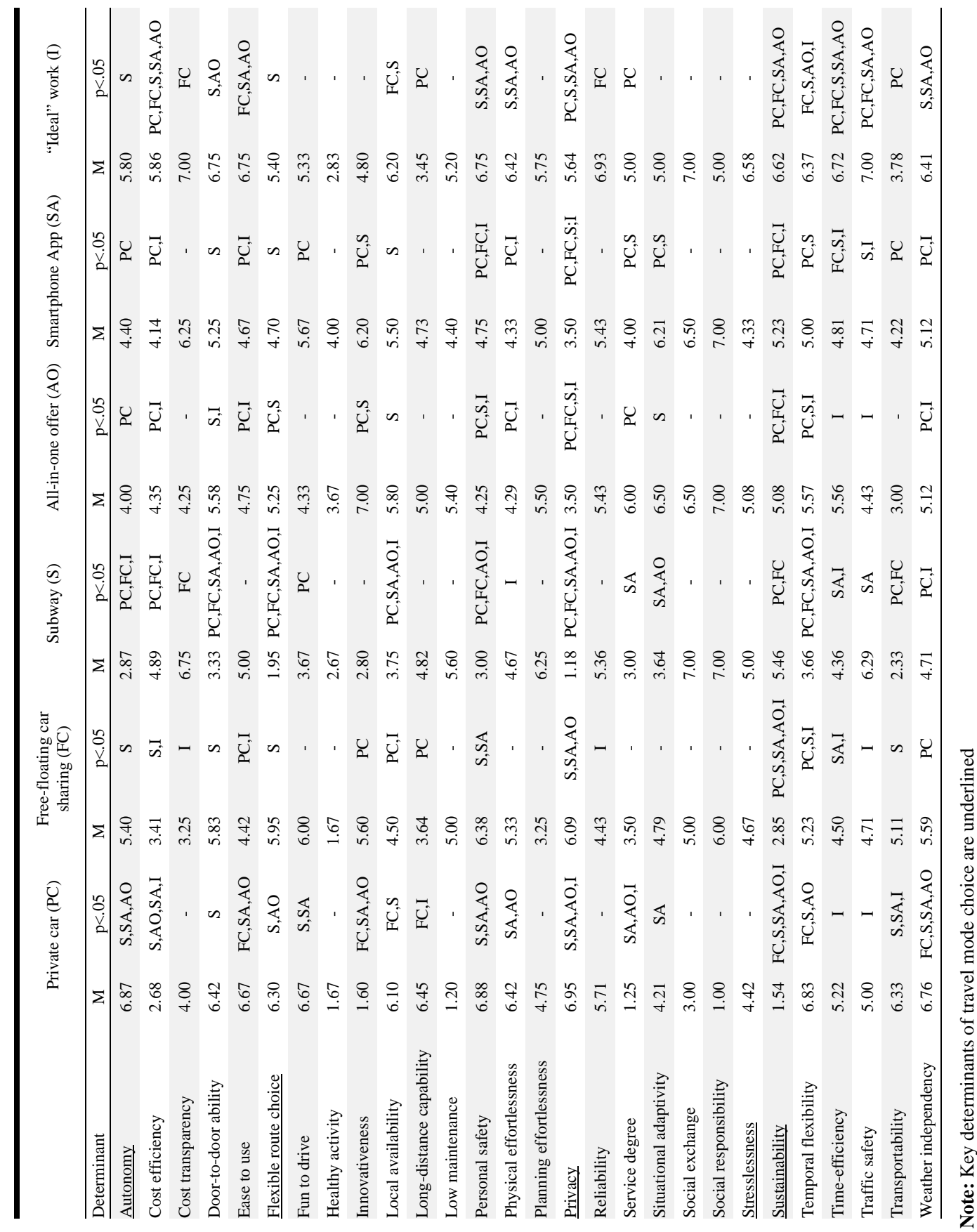


Figure A.1

Example repertory grid (participant 35, private car user)

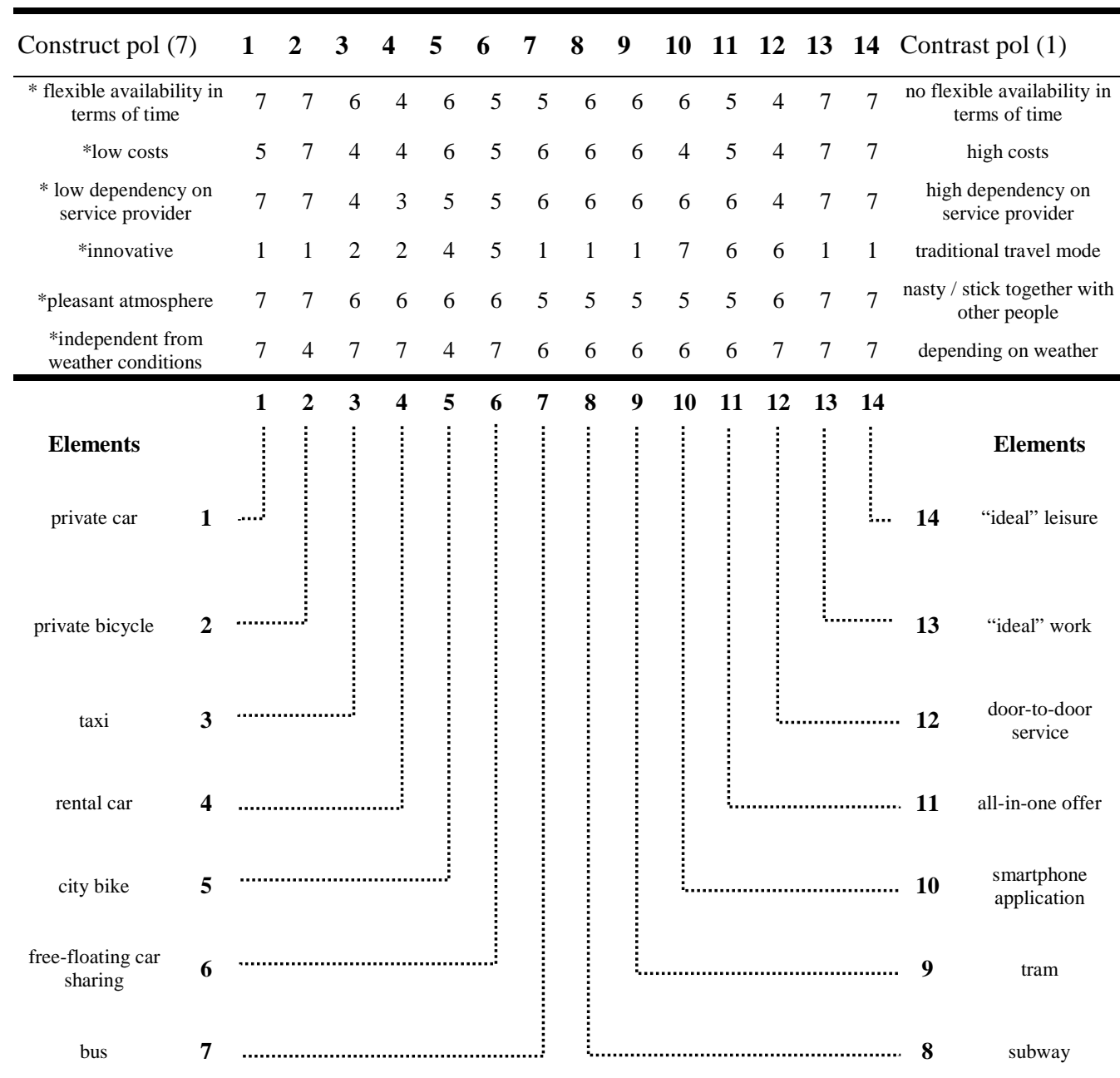

Note: Each row in the grid represents a personal construct elicited by comparison of the elements (i.e. travel modes) in the columns.

Each construct was rated from 1 to $7(1$ = contrast pole fully applies (e.g. "no flexible availability in terms of time); 7 = construct pole fully applies (e.g. "flexible availability in terms of time)) for all 14 urban travel modes.

$\left(^{*}\right)$ Asterisks mark the perceived positive pole from the perspective of the participant 
Figure A.2

Methodological Procedure

\section{Repertory Grid interview procedure}

1. Decide on the focus of the grid

Purpose: Precise definition of the topic to explore

Content: Literature review of previous studies to define the scope of urban travel modes

\section{Selection of appropriate elements}

Purpose: Assessment of relevance

Content: Selection and description of existing and innovative mono- and multimodal urban travel modes to be used as elements in the RGT interview

\section{Elicitation of constructs from the elements}

Purpose: Identification of individual perception-based constructs about travel modes

Content: Elicitation of constructs based on triads of travel modes (3 out of 14 elements)

\section{Linking constructs to elements}

Purpose: Quantification of constructs

Content: Assessment of the elements based on the elicited constructs with a 7-point scale

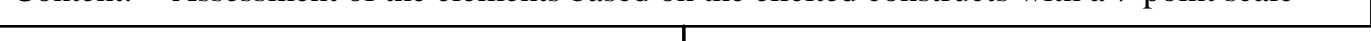

\section{Repertory Grid analysis procedure}

\section{Aggregation of the elicited constructs of travel mode choice}

Purpose: Aggregation of the 366 constructs of travel mode choice which were elicited during the interviews

Content: Utilization of a content based bootstrapping procedure by two independent coders and reliability check

\section{Identification of perceptual dimensions of travel mode choice}

Purpose: Identification of six perceptual dimensions of travel mode choice each comprising a set of particular determinants of travel mode choice

Content: Utilization of an exploratory principle component analysis to extract core dimensions

\section{Identification of key determinants of travel mode choice}

Purpose: Identification of the five most important key determinants of travel mode choice

Content: Assessment of the determinants based on variability and frequency measures

\section{Comparison of travel modes}

Purpose: Characterization and comparison of existing and ideal travel modes based on the determinants of travel mode choice to deduce recommendations for policy making and management

Content: Quantitative pairwise comparison of travel modes using an analysis of variance with Tuckey post-hoc procedure 
Figure A.3

Procedure of the Interview (steps and exemplary excerpts)

\section{Step 1: Introducing the research topic to the participant}

The interviewer gave a short introduction by highlighting the scientific focus and the objective of the research. Additionally, the interviewer asked the participant about their familiarity with the traditional travel modes and explained the 3 innovative travel modes (see Table A.1) in more detail. After discussing the elements the interviewer introduced the RGT by giving an example of the triad presentation procedure different from the mobility sector.

\section{Step 2: Elicitation of constructs Step 2.1: Triad presentation (1 out of 6 )}

\section{Presenting a triad (3 travel modes at a time) and elicitation of constructs}

Triad presentation (1/6) E1: City bike E2: Free-floating car sharing E3: Subway

Interviewer: "When you think about these three alternative travel modes, regarding which determinant are two of these travel modes similar but different from a third one.” (Kelly question)

Participant: "It's more difficult than I thought. Well, my first idea was that the subway and the free-floating car sharing fit together."

Construct elicitation (corresponding determinants: long distance capability, local availability, transportability) Participant: "You can tackle longer distances with the subway and the car sharing in comparison with the city bike [...] For me personally, it's [the city bike] just for short distances. [...] And I think the availability of the subway and the car sharing is better. Frequently I see empty city bike stations [...] Oftentimes I pass the university district and I can't see any bikes at all... That's why I think the availability of the subway and the car sharing is higher compared to the city bike [...] And I can transport different thinks. Not much, neither with the free-floating car sharing nor with the subway, but a suitcase when travelling around.”

Linking constructs to elements

After each elicitation phase, the interviewee rated each of the 14 elements based on the new constructs (i.e. long distance capability, local availability, transportability) using a seven-point scale ranging from 1 (construct pole fully applicable) to 7 (contrast pole fully applicable)

\section{Step 2.2: Triad presentation (2 out of 6 )}

Triad presentation (2/6) E1: Private bike E2: Taxi E3: Tram

Interviewer: Repeated Kelly question

Participant: "[...] the taxi and the tram go together."

Elicited constructs (corresponding determinant: weather dependency)

Participant: "the bike and the taxi [...] both providing privacy. [...] at the weekend, at night... that's when I take the taxi because a group of drunken guys could walk past [...] with the taxi as well as with the private bike you can be for yourself. [...] Another point is the weather dependency. Sometimes there are icy roads so I don't want to take the taxi and the weather conditions for the bike are bad too, comparing to the tram or anything else that runs on rails. When I lived in Finland... I would always take the tram but not the bus or the taxi. It's not that important in Hamburg but there are days I prefer the tram."

Linking constructs to elements (repeated rating procedure)

\section{Step 2.3: Triad presentation (3 out of 6 )}

Triad presentation (3/6) E1: Rental car E2: Bus E3: City bike

Interviewer: Repeated Kelly question

Participant: “...I would say the rental car stands alone and the other two go together."

Elicited constructs (corresponding determinants: autonomy, cost efficiency)

Participant: "It's about being self-determined or not. Means the bus and the city bike [...] I take what comes along. When I take the bus I have to take the way the bus takes and when I take the city bike I can take into consideration where I can return the bike, for example. So I'm dependent on the network and on the vehicles that come along. With the rental car I can decide what, where, when and where I drive... that's more of a fully free self-determination" [...] and the rental car is more expensive, of course"

Linking constructs to elements (repeated rating procedure) 


\section{Step 2.4: Triad presentation (4 out of 6)}

Triad presentation (4/6) E1: Private car E2: Smartphone-application E3: Private bike

Interviewer: Repeated Kelly question

Participant: “...the private car and the private bike go together. From my point of view. That's what comes to my mind first...”

Elicited constructs (corresponding determinant: reliability)

Participant: “... and being independent from a smartphone app, having a signal, registration processes. I simply can use it... without transmitting data somewhere... no one knows where I am... [laughing]

Interviewer: "Do you mean a service dependency too?"

Participant: "Yes, where I come from the cell phone reception isn't always that good, I'm sure it's better in the city but even there the mobile phone runs out of juice because it's always searching for a hotspot or a signal because the service is interrupted in the subway. Yesterday, for example, we went out of the subway station to get a Car2Go and via my mobile device and it took me 15 minutes just to find it but it doesn't work. Finally, outside of the subway station I was able to reserve and localize the car [...] that's a bit annoying.

Linking constructs to elements (repeated rating procedure)

\section{Step 2.5: Triad presentation (5 out of 6)}

Triad presentation (5/6) E1: Taxi E2: Rental car E3: All-in-one offer

Interviewer: Repeated Kelly question

Participant: “...I would say one [E1: taxi] and two [E2: rental car] belong together.

Elicited constructs (corresponding determinants: flexible route choice; situational adaptivity)

Participant: They (taxi and rental car) both use the street, both are vehicles und you can reach the same destinations with them. When talking about route dependency, obviously, the taxi and the rental fits together well [...]. Well, it's the intermodality. You can change your strategy... you can optimize the journey being on the way, I do like that a lot. Like yesterday, when I saw a traffic jam I spontaneously change from the car to the subway [...] let's say it's about the choice within the offer."

Linking constructs to elements (repeated rating procedure)

\section{Step 2.6: Final triad presentation (6 out of 6)}

Triad presentation (6/6) E1: Door-to-door service E2: Free-floating car sharing E3: All-in-one offer Interviewer: Repeated Kelly question

Participant: “...to me one (door-to-door service) and three (private car) belong to one category...”

Elicited constructs (corresponding determinants: door-to-door ability; personal safety)

Participant: "[...]because both of them are able to take me from door to door but that's not the case with the car sharing because you're possibly leaving the operational area"

Interviewer: "When you think about all considered mobility alternatives again, is there anything else that could be a selection criterion for you? Did we miss any attributes that are important to you but are not written down yet?”

Participant: "Yes, in fact how comfortable and save you feel. Because sometimes it happens that there are riots or drunken people or it smells disgusting. It's about well-being and safety. From my point of view it is linked to each other."

Linking constructs to elements (repeated rating procedure) 